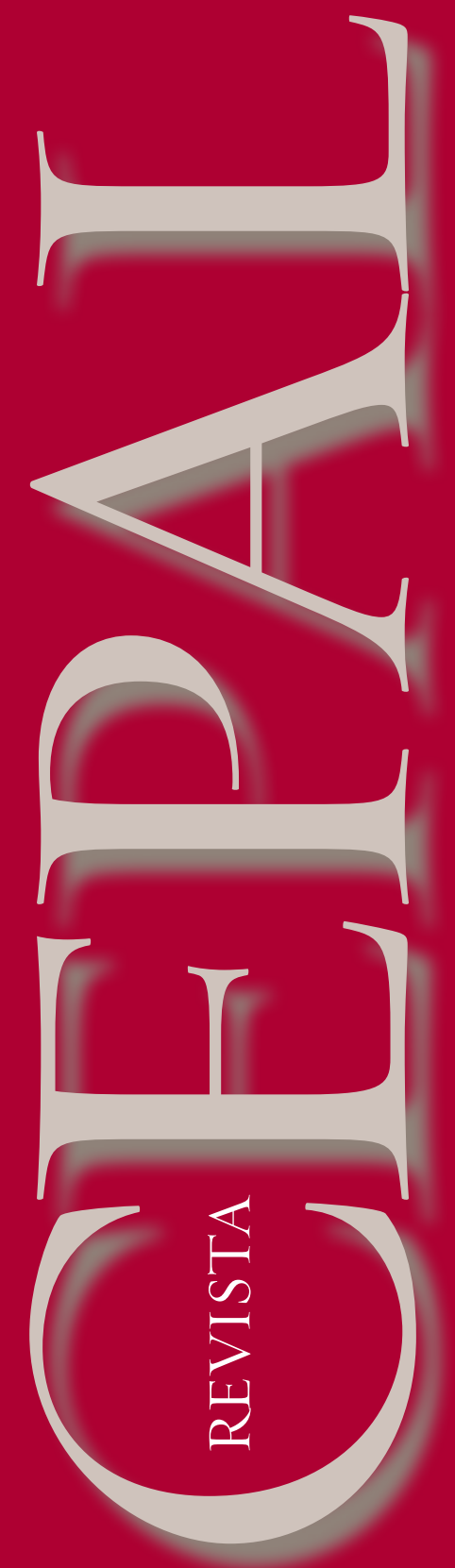

COMISIÓN ECONÓMICA PARA AMÉRICA LATINA

Y EL CARIBE

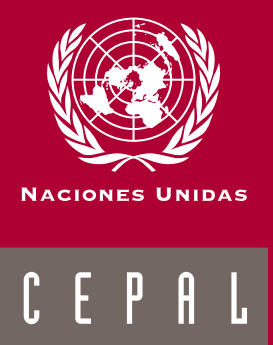

SEPARATA

Redes de conocimiento asociadas a la producción de recursos naturales en América Latina: análisis comparativo

Valeria Arza, Anabel Marín, Emanuel López y Lilia Stubrin 


\title{
Redes de conocimiento asociadas a la producción de recursos naturales en América Latina: análisis comparativo ${ }^{1}$
}

\author{
Valeria Arza, Anabel Marín, Emanuel López y Lilia Stubrin
}

\section{Resumen}

Las oportunidades para innovar que surgen vinculadas con la producción de recursos naturales se asocian a la conformación de redes de conocimiento que facilitan el aprendizaje dentro y fuera de estos sectores. El artículo identifica los tipos de redes de conocimiento asociadas a actividades de innovación en materia de recursos naturales, utilizando cuatro casos de estudio en la región: el sector ganadero en la Argentina, el minero en Chile, el agrícola en el Paraguay y el forestal en el Uruguay. Nuestros resultados muestran que, en los cuatro casos, los productores de recursos naturales forman redes en las que se intercambia conocimiento científico. Las redes identificadas tienen características heterogéneas en términos de las capacidades de los actores, la estructura y el nivel de apertura. Sin embargo, en todas ellas hallamos potencial para difundir y crear conocimiento.

\section{Palabras clave \\ Recursos naturales, innovaciones, gestión del conocimiento, información científica y técnica, estudios de casos, América Latina, Argentina, Chile, Paraguay, Uruguay \\ Clasificación JEL}

D83, Q16, L23

\section{Autores}

Valeria Arza es Directora del Centro de Investigaciones para la Transformación (CENIT) de la Universidad Nacional de San Martín (UNSAM), e Investigadora en el Consejo Nacional de Investigaciones Científicas y Técnicas (CONICET), Argentina. Correo electrónico: varza@fund-cenit.org.ar.

Anabel Marín es Investigadora en el Centro de Investigaciones para la Transformación (CENIT) de la Universidad Nacional de San Martín (UNSAM), e Investigadora en el Consejo Nacional de Investigaciones Científicas y Técnicas (CONICET), Argentina. Correo electrónico: a.i.marin@fund-cenit.org.ar.

Emanuel López es Becario Doctoral en el Consejo Nacional de Investigaciones Científicas y Técnicas (CONICET), Argentina. Correo electrónico: elopez@fundcenit.org.ar.

Lilia Stubrin es Investigadora en el Centro de Investigaciones para la Transformación (CENIT) de la Universidad Nacional de San Martín (UNSAM), e Investigadora en el Consejo Nacional de Investigaciones Científicas y Técnicas (CONICET), Argentina. Correo electrónico: Istubrin@fund-cenit.org.ar.

\footnotetext{
La evidencia empírica de esta investigación está basada en cuatro estudios de caso que se llevaron a cabo en el marco del proyecto "Oportunidades para generar valor en la producción de recursos naturales: actividades de innovación y redes de conocimiento en el Cono Sur", financiado por la Red Mercosur. Agradecemos a todos los investigadores que participaron en el proyecto. La base del presente trabajo son los correspondientes informes nacionales, a saber: Aboal, Rovira y Veneri (2014); Arza, López y Marín (2014); Benavente y Price (2014), y Servín y Rojas (2014).
} 


\section{Introducción}

Hasta hace muy poco, las actividades basadas en recursos naturales se asociaban con un bajo potencial de crecimiento económico y un pobre dinamismo tecnológico. En la década de 1950, se argumentaba que esta asociación se debía a la tendencia al deterioro de los términos de intercambio de los productos basados en recursos naturales (Prebisch, 1962; Singer, 1950), a las fluctuaciones de los precios de los productos básicos que se basan en dichos recursos (Levin, 1960; Nurkse, 1958), al bajo potencial para el progreso técnico que estos sectores tienen en comparación con el de las manufacturas (Prebisch, 1962) y a la poca capacidad de las industrias en las que se trabaja con recursos naturales para establecer encadenamientos con el resto de la economía (Singer, 1950; Hirschman, 1961; Singer, 1975). En los años sesenta, el fenómeno de la enfermedad holandesa y algunos estudios empíricos posteriores aportaron evidencia adicional en favor de la idea de la maldición de los recursos naturales (Auty, 1993 y 1997; Gelb, 1988; Gylfason, Herbertsson y Zoega, 1999; Nankani, 1980; Sachs y Warner, 1995; Wheeler, 1984). En este marco, fue consolidándose la idea de que, en el corto plazo, los recursos naturales podían contribuir a superar la restricción externa aprovechando ventajas comparativas estáticas, pero que, en el mediano y largo plazo, no favorecían la creación de ventajas dinámicas debido a las pocas oportunidades para innovar que ofrecían y a sus débiles lazos con otros actores de la economía. Por lo tanto, en los países ricos en recursos naturales se debía generar una transformación estructural hacia otras actividades más dinámicas, como las manufactureras.

Sin embargo, en las últimas décadas, esta visión ha ido cambiando en asociación con importantes transformaciones de orden económico, tecnológico, institucional y social, que han comenzado a crear nuevas oportunidades para innovar e incorporar valor en las actividades relacionadas con los recursos naturales (Marín, Stubrin y Da Silva, 2015; Pérez, 2010). Entre los cambios más relevantes podemos señalar los siguientes: la modificación de los patrones de demanda, caracterizados por el aumento de la demanda de recursos naturales, la mayor segmentación de esta y la aparición de nichos dinámicos en estos sectores; la difusión de nuevas tecnologías intensivas en conocimiento, como la biotecnología, la nanotecnología y las tecnologías de la información y las comunicaciones (TIC), que permiten diversificar y desarrollar nuevos productos en torno a los recursos naturales, y los cambios institucionales, como la posibilidad de patentar materia viva (Marín, Stubrin y Da Silva, 2015; Pérez, 2010). Junto con estos cambios, crece el reconocimiento de que las actividades vinculadas con los recursos naturales generan diversas oportunidades cada vez más importantes para crear valor (Andersen, 2015; Andersen y otros, 2015; Dantas, 2011; Marín, Navas-Aleman y Pérez, 2015; Marín y Stubrin, 2015; Smith, 2007; Ville y Wicken, 2012).

La literatura empírica sobre las nuevas oportunidades de innovación asociadas a los recursos naturales está creciendo, pero todavía es limitada (Crespi, Katz y Olivari, 2016; Dantas, 2011; Figueiredo, 2010; lizuka y Katz, 2015; Marín, Stubrin y Da Silva, 2015; Morris, Kaplinsky y Kaplan, 2012). En este trabajo hacemos una contribución a esta literatura emergente, al explorar oportunidades de innovación asociadas a cuatro actividades que están relacionadas con los recursos naturales y son importantes en América Latina. Más específicamente, nos focalizamos en un fenómeno que está adquiriendo una importancia creciente: las oportunidades que están creando las actividades vinculadas con los recursos naturales para generar valor "aguas arriba", a través de redes que emergen con el objeto de aportar el conocimiento que el sector necesita para llevar adelante actividades de innovación.

La extensión de la base de conocimiento científico y sus aplicaciones es un elemento central de cualquier proceso de desarrollo económico. En la producción de recursos naturales cada vez se incorpora más conocimiento científico a fin de crear nuevos productos y de que los procesos de extracción y procesamiento de dichos recursos sean más eficientes e inocuos para el medio ambiente (Marín, Navas-Alemán y Pérez, 2015; Pérez, 2010). El desarrollo y la aplicación de nuevo conocimiento en el ámbito de las actividades productivas en general requieren de redes de 
conocimiento que involucren distintos tipos de actores provenientes de los ámbitos tanto productivos como científicos. Este tipo de redes facilitan la obtención y el intercambio de conocimiento que existe de forma dispersa, y favorecen la innovación (Etzkowitz y Leydesdorff, 2000; Lundvall y otros, 2002; Mazzoleni y Nelson, 2007).

Entendemos que, si las actividades vinculadas con los recursos naturales están dando lugar a oportunidades para que surjan redes de conocimiento o se amplíen las que ya existen, habrá ocasión para que las firmas que forman parte de la red escalen hacia actividades de mayor valor agregado, para la participación de otros actores que subsecuentemente se relacionen con alguno de los actores de la red y, más en general, para la ampliación de la base de conocimiento, lo que dinamizaría el sistema en su conjunto. En este trabajo, con el objetivo de analizar las nuevas oportunidades de crear valor que los sectores de los recursos naturales están generando, proponemos estudiar en profundidad las redes de colaboración que se han establecido a partir de las necesidades de conocimiento científico biotecnológico de cuatro sectores de recursos naturales seleccionados: el ganadero, en la Argentina; el minero, en Chile; el agrícola, en el Paraguay, y el forestal, en el Uruguay. Los sectores seleccionados tienen un gran peso en la economía de los cuatro países estudiados y una tradición muy importante de innovación en la región. Además, elegimos la biotecnología como área de conocimiento y tecnología presente en los cuatro sectores debido a que esta área ocupará un lugar central en las próximas fases de crecimiento de la economía mundial (Pérez, 2010) y encuentra un campo de aplicación muy fértil en la producción de recursos naturales.

Con el objetivo de entender el impacto potencial que el desarrollo de redes de conocimiento de recursos naturales puede tener sobre la creación de valor, caracterizamos las distintas redes seleccionadas de acuerdo con un conjunto de dimensiones que en la literatura se han identificado como importantes a fin de explicar las capacidades que dichas redes tienen para innovar y difundir conocimiento. Nuestros resultados muestran que, efectivamente, existen redes de intercambio y creación de conocimiento científico asociadas a las actividades de innovación en materia de recursos naturales. En todos los casos estudiados, en términos de las capacidades de los actores y la estructura de la red, estas redes muestran alguna de las características que en la literatura se han identificado como promisorias respecto de la difusión y creación de conocimiento científico.

El presente artículo está dividido en seis secciones. En la sección II, se examina el marco conceptual de la investigación y se obtienen las proposiciones que guiarán el trabajo empírico. Más específicamente, se señala cuáles son, de acuerdo con la literatura, las características que favorecen la creación y difusión de conocimiento. En la sección III, se caracterizan los sectores productivos seleccionados en cada país, en términos de su evolución reciente y de los rasgos fundamentales de la innovación en cada uno de ellos. En la sección IV, se describe la metodología de recolección y análisis de los datos. En la sección V, se analizan las redes y su potencial para crear y difundir conocimiento, evaluando las capacidades de los actores, la estructura de la red y el nivel de apertura. Por último, en la sección VI, se formulan conclusiones y se mencionan las implicaciones en el ámbito de las políticas.

\section{II. ¿Cuáles son las redes que más favorecen la creación y difusión de conocimiento?}

Es común que la actividad innovadora se desarrolle en el marco de redes de conocimiento, sobre todo cuando involucra la resolución de problemas complejos que las firmas no pueden resolver a nivel individual, por lo que recurren al conocimiento que puede aportar una multiplicidad de actores (Mazzoleni y Nelson, 2007). La generación y aplicación de nuevos conocimientos en el ámbito productivo en general es una actividad costosa y de resultados inciertos. Las empresas privadas, por 
lo tanto, se asocian con otras para compartir los costos y los riesgos, y recurren a socios provenientes de la comunidad científica para acceder a conocimientos que no se encuentran en la esfera industrial (Lundvall y otros, 2002).

En la literatura se han señalado numerosos ejemplos de redes de conocimiento que han creado oportunidades de aprendizaje para los actores que participan en ellas, tanto en los países desarrollados como en los países en desarrollo (Bell y Giuliani, 2007; Cabral, 1998; Etzkowitz, Carvalho de Mello y Almeida, 2005; Giuliani, 2013; Schmitz y Nadvi, 1999; Stubrin, 2013)². Los beneficios que se derivan de las redes de conocimiento, sin embargo, no se limitan a los actores que participan en ellas, ya que los nuevos conocimientos generados para abordar los problemas de innovación dentro de la red pueden también utilizarse en otras redes y actividades productivas, lo que dinamiza el sistema en su conjunto. Es decir, el conocimiento y las tecnologías que se crean en un contexto específico, como la producción de recursos naturales, podrían ser útiles para otras actividades productivas, en un proceso que Lorentzen (2005) denominó "migración lateral".

Sin embargo, no todas las redes dan lugar a las mismas oportunidades para innovar y difundir conocimiento. Las redes pueden diferenciarse según los tipos de actores (los nodos) que las componen, sus capacidades, la distribución de estas capacidades en la red y el tipo de conocimiento que se intercambia. A su vez, los vínculos entre los nodos producen redes con diferentes estructuras (jerárquicas, centralizadas, con altos grados de incrustación, dispersas y otras) que afectan el desempeño individual y el de la red en su conjunto.

En general, en la literatura se ha encontrado que las capacidades de los actores que participan en las redes son claves tanto para generar innovaciones como para difundir el conocimiento dentro y fuera de la red (Giuliani, 2013; Giuliani y Bell, 2005). Por ejemplo, se ha hallado que, en las redes en las que participan firmas que tienen mayores capacidades, hay más probabilidades de que ocurran intercambios de conocimiento y de que la evolución en el tiempo sea positiva. Esto es así porque las firmas dotadas de mayores capacidades tienen recursos para compartir y en general buscan complementar sus capacidades con otras existentes en la red. Cuando se trata de firmas con capacidades limitadas, se da el efecto contrario. Altenburg y Meyer-Stamer (1999) señalan que, en entornos donde la capacidad es baja, la cultura de la imitación hace que los empresarios sean reacios a compartir cualquier tipo de información y que existan comportamientos oportunistas o incluso depredadores (pág. 1697). Además, las firmas con más capacidades tienen más chances de que las busquen para colaborar en distintos proyectos, y tienen una posibilidad mayor de absorber y reutilizar el conocimiento que fluye dentro de la red de manera provechosa para ellas mismas y para la red en su conjunto (Giuliani y Arza, 2009). Podríamos decir, entonces, que es particularmente importante que los actores que ocupan un lugar central en la red y que por tanto tienen más oportunidades para difundir conocimiento dentro de ella tengan mayores capacidades.

El grado de similitud entre los actores en cuanto al nivel de conocimiento también se ha señalado como una variable importante para explicar el establecimiento de vínculos y la socialización del conocimiento (Giuliani, 2013; Giuliani y Bell, 2005). Cuando las empresas tienen un nivel de conocimiento avanzado, prefieren establecer vínculos de conocimiento con empresas que tienen un nivel de tecnología o conocimiento similar. Esto ocurre en parte porque las empresas solo tienen incentivos para establecer vínculos si entienden que pueden beneficiarse de la interacción (Giuliani, 2007). Si las bases de conocimiento son demasiado diferentes, la vinculación y la socialización de este serán menos probables. Se requiere, por lo tanto, que el mínimo de capacidad de las redes sea relativamente alto.

\footnotetext{
2 Por ejemplo, en la literatura se ha documentado cómo, en el caso de la industria del carbón en Sudáfrica, la necesidad de lavar el carbón extraído (debido a su mala calidad) incentivó el desarrollo de capacidades y productos que migraron a otras áreas - como el lavado de espirales en las arenas bituminosas del Canadá (Morris, Kaplinsky y Kaplan, 2012) -, a través de las redes productivas y de conocimiento que se crearon en dicha actividad.
} 
En la literatura también se señala la necesidad de complementar el conocimiento, ya que las empresas buscan puertas afuera aquellos conocimientos y competencias que no poseen puertas adentro. En particular, en el caso de las industrias más dinámicas desde el punto de vista tecnológico, la complejidad y extensión de la base de conocimiento necesaria para competir incentiva a las empresas a establecer alianzas con otros agentes a fin de acceder a nuevo conocimiento. Estas alianzas no se establecen entre dos firmas al azar, sino, sobre todo, entre aquellas que comparten cierta base de conocimiento común, pero que también tienen cierto conocimiento diferencial que justifica la colaboración (Ahuja y Katila, 2001; Duysters y Schoenmakers, 2006; Gulati y Gargiulo, 1999; Mowery, Oxley y Silverman, 1996).

En términos de estructura, las redes en las que todos los actores que participan tienden a estar conectados entre sí (aglomeración) parecen favorecer la difusión y creación de nuevo conocimiento dentro de la red (Cowan, 2005). Algunos autores sostienen que las redes en las que cooperan actores que tienen contactos en común (fenómeno que se denomina "incrustación estructural") son generalmente ricas en capital social (Coleman, 1988). En este tipo de redes, las conductas oportunistas tienden a minimizarse, ya que las firmas tienen incentivos para preservar su reputación en la red a fin de mantener sus posibilidades de colaborar y participar. En parte de la literatura se considera que esas características son valiosas para favorecer la circulación y el intercambio de conocimiento entre los miembros de la red, lo que puede, a su vez, fortalecer la capacidad de innovación de las firmas. Desde una perspectiva empírica, se ha encontrado que la incrustación estructural es significativa para explicar la capacidad de innovación y aprendizaje de las firmas en industrias como la textil (Uzzi, 1996) y la biotecnológica (Ahuja, 2000; Powell y otros, 1999), y en las tecnologías de la información y las comunicaciones (TIC) (Hagedoorn y Duysters, 2000).

En la literatura también se ha enfatizado el valor de la reciprocidad (Ahuja, Soda y Zaheer, 2012; Giuliani, 2013). Hay reciprocidad cuando cada firma da y recibe. Se argumenta que esta característica favorece el desarrollo de vínculos y la socialización del conocimiento, ya que reduce los desequilibrios y las relaciones de poder. Además, la reciprocidad actúa de forma contraria al oportunismo. Una reputación de comportamiento oportunista no favorece la socialización ni la circulación de conocimiento; la reciprocidad, por el contrario, favorece la socialización del conocimiento y el establecimiento de nuevos vínculos.

Asimismo, los vínculos o lazos con agentes situados fuera de la red son críticos para favorecer y sostener la competitividad de las empresas, ya que pueden proveer nuevos conocimientos y renovar las bases de estos (Breschi y Malerba, 2001). Estos vínculos pueden ser especialmente importantes en actividades nuevas y dinámicas, sujetas a fuertes cambios tecnológicos, ya que establecer vínculos con agentes externos a la red (con los cuales no se tiene una relación previa ni se está conectado de forma indirecta) puede permitir el acceso a conocimiento nuevo y diverso, así como a recursos que permitan obtener una ventaja en el mercado o simplemente evitar el encajonamiento tecnológico (lock-in). Por ejemplo, en la industria biotecnológica (Rees, 2005) y en la de los semiconductores (Rosenkopf y Almeida, 2003), se halló que las alianzas con agentes localizados en otras regiones eran valiosas para renovar la base de conocimiento de los agentes locales.

En suma, en la literatura se destaca la importancia de algunas dimensiones, tanto en términos de las características de los nodos como de los vínculos, para que las redes de conocimiento tengan un buen desempeño en cuanto a la generación de innovaciones y la difusión de conocimiento. Sobre la base de estas ideas, entendemos que las redes tenderán a ser más efectivas cuando se cumplan las proposiciones que se indican a continuación.

En relación con las capacidades:

1) Que la capacidad promedio de los actores sea alta.

2) Que todos los actores tengan un mínimo elevado de capacidades. 
3) Que los actores que ocupan un lugar central de la red como emisores de conocimiento tengan altas capacidades.

En cuanto a la cohesión:

4) Que en la red haya un alto nivel de aglomeración.

5) Que en la red haya un nivel elevado de reciprocidad.

6) Que se observe un nivel alto de incrustación estructural (transitividad).

En relación con la apertura de la red:

7) Que se establezcan lazos fuera del núcleo central de la red.

8) Que los actores externos tengan capacidades altas respecto del núcleo.

En lo que sigue, luego de presentar los casos (véase la sección III) y la metodología (véase la sección IV), analizamos las redes (véase la sección V) respecto de las capacidades de los actores, la cohesión y el nivel de apertura.

\section{Los sectores estudiados y sus redes de conocimiento para la innovación}

Estudiamos las actividades innovadoras y las redes de conocimiento en cuatro sectores de recursos naturales de cuatro países: el sector ganadero, en la Argentina; el minero, en Chile; el agrícola, en el Paraguay, y el forestal, en el Uruguay. Recientemente, en estos sectores seleccionados se han hecho esfuerzos innovadores importantes para enfrentar nuevos desafíos. A continuación, describimos cada caso de forma breve.

\section{El sector ganadero en la Argentina}

Históricamente, el sector ganadero ha tenido un peso importante en la producción agropecuaria y las exportaciones argentinas, pero desde los años noventa se han enfrentado dificultades asociadas tanto a la disputa por la tierra - dado el avance de las actividades agrícolas, sobre todo las relacionadas con la soja-, como a conflictos con políticas públicas nacionales orientadas a garantizar la provisión de carne en el mercado interno a precios accesibles ${ }^{3}$. A pesar de estos desafíos, las existencias de ganado bovino se han mantenido relativamente estables en la Argentina (alrededor de 50 millones de cabezas), en virtud de un proceso de intensificación productiva orientada a incrementar la eficiencia y aumentar la calidad cárnica vía el mejoramiento genético. Las herramientas biotecnológicas, como la inseminación artificial, la fecundación in vivo, la fecundación in vitro y el sexado de embriones y de semen, han sido elementos centrales de este proceso ${ }^{4}$. Estas herramientas se utilizan para modificar el perfil genético del animal. Las mejoras genéticas introducidas luego se transmiten con la propiedad del animal reproductor o a través de la comercialización de semen o de embriones de reproductores seleccionados. Para nuestro caso de estudio, seleccionamos una red de conocimiento sobre mejoramiento genético bovino.

3 Con ese fin, a partir de 2006, el Gobierno nacional introdujo una serie de políticas, como la restricción de las exportaciones de carne, el incremento de las alícuotas de retenciones, el control de precios en diferentes etapas de la cadena productiva y el establecimiento de pesos mínimos de faena.

4 Otra herramienta ha sido la genética cuantitativa, que se utiliza para evaluar ciertas características de interés económico de los animales (por ejemplo, el peso al nacer, el peso al destete, la terneza de la carne, la cantidad y la ubicación de la grasa, y el nivel de producción de leche, entre otras). Estas mediciones luego se utilizan en el proceso de selección que realizan las empresas "productoras" de animales reproductores (que suelen denominarse "criadores" o "cabañas"). 


\section{El sector minero en Chile}

La industria minera ha desempeñado un papel central en el crecimiento económico de Chile, que es el principal productor de cobre del mundo (34\% de la producción mundial) y es dueño de casi el 30\% de las reservas mundiales de ese mineral ${ }^{5}$. En la actualidad, sin embargo, el sector minero enfrenta numerosos desafíos, como la reducción de las leyes del mineral y el incremento de los costos de la energía y el agua. Para abordar estos desafíos, cada vez se recurre más a proveedores innovadores (Fundación Chile, 2012 y 2014). Entre los proveedores de la minería se destacan aquellos que brindan servicios basados en conocimiento científico. Un caso significativo ha sido el desarrollo del proceso biotecnológico llamado biolixiviación, que permite separar el mineral de la roca y requiere menos agua y energía que los métodos alternativos tradicionales. Actualmente, alrededor del $10 \%$ de la producción total de cobre en Chile (más de 500.000 toneladas de cobre fino) se obtiene a través de esta nueva tecnología, y se estima que su uso se incrementará a medida que las fuentes del mineral se vayan acabando. En 2009, había siete operaciones de biolixiviación controladas por cinco grupos mineros diferentes (COCHILCO, 2009). Para nuestro caso de estudio, seleccionamos una red de conocimiento asociada a soluciones biotecnológicas que se utilizan en la minería.

\section{El sector triguero en el Paraguay}

La producción de trigo en el Paraguay es estratégica, ya que este cereal ocupa un lugar prioritario en la canasta alimentaria. Hacia finales de la década de 1980, gracias al uso de variedades de mejor rendimiento y a tecnologías más eficientes de producción (uso de fertilizantes, control químico de enfermedades y cultivo en las épocas adecuadas, entre otras), el país logró autoabastecerse y exportar trigo. Hoy en día, el trigo ocupa el quinto lugar entre los cereales que produce el país, con más de 600.000 hectáreas sembradas. Sin embargo, la gran expansión de la soja a nivel nacional ha creado la necesidad de mantener la producción de trigo, que funciona como cultivo alternativo a la soja en temporada de invierno. Esto hizo necesario incrementar la eficiencia y adaptar su producción hacia zonas que por naturaleza no son aptas para él ${ }^{6}$. Con ese objetivo, el sector triguero está llevando a cabo una gran labor innovadora basada en la difusión de nuevas y mejores prácticas agronómicas y en el mejoramiento genético de las semillas. Para nuestro caso de estudio, seleccionamos una red de conocimiento que se basa en esas técnicas.

\section{El sector forestal en el Uruguay}

En el Uruguay, la actividad forestal ha mostrado un gran crecimiento en las últimas décadas y ha llegado a posicionarse como el tercer sector exportador más importante del país (detrás de la carne y la soja). Este gran crecimiento del sector ha estado asociado a la expansión del área forestada y de la producción. La primera pasó de 650.000 a 1 millón de hectáreas entre 2000 y 2012, y la segunda se triplicó con creces en el período 2000-2011, al pasar de aproximadamente 3 millones de metros cúbicos en 2000 a 10 millones en 2011. La actividad innovadora y la introducción de cambios tecnológicos han sido centrales en este crecimiento (Bervejillo, Mila y Bertamini, 2011). La innovación se orienta a introducir cambios genéticos en las especies que se utilizan para la producción y a disminuir el tiempo que transcurre desde la selección de un árbol hasta su explotación comercial.

5 En 2012, el valor de la producción minera en Chile representó el 12\% del producto interno bruto (PIB), las exportaciones mineras alcanzaron un valor equivalente al $60 \%$ de las exportaciones totales, y el aporte al erario público fue equivalente al $14 \%$ de los ingresos fiscales.

6 De acuerdo con datos de la Cámara Paraguaya de Exportadores y Comercializadores de Cereales y Oleaginosas (CAPECO), entre la campaña de 2002 y 2003 y la de 2013 y 2014, la superficie de producción de soja se duplicó con creces y pasó de 1,5 a 3,5 millones de hectáreas. 
En nuestro caso de estudio, nos concentramos en la segunda de estas actividades de innovación, que se realiza en dos etapas. La primera tiene lugar en los laboratorios de micropropagación, donde los tejidos vegetales se cultivan de manera aséptica y se logra incrementar de forma exponencial el volumen de microplantas en tiempo y espacio reducido. La segunda transcurre en el vivero, donde se lleva a cabo la propagación final mediante reproducción vegetativa (con estacas) de plantas madres.

\section{Metodología}

\section{Diseño de la investigación}

El principal objetivo de este trabajo es reconstruir y caracterizar las redes asociadas a las necesidades de conocimiento de cuatro sectores de recursos naturales en cuatro países de la región. Con este objetivo, en cada país se seleccionó un actor clave para el desarrollo de conocimiento orientado a resolver los problemas de los proveedores de recursos naturales. A ese actor se lo llamó "ego de la red" y, a partir de él, se reconstruyó la red de conocimiento incluyendo otros actores con los que ese actor se vinculaba para intercambiar conocimiento.

En la Argentina, las empresas de recursos naturales que estudiamos son las cabañas o empresas que desarrollan y venden genética bovina. A fin de reconstruir la red de conocimiento de las cabañas, identificamos un actor que es central para ellas en términos de intercambio de conocimientos asociados al uso de la biotecnología para el mejoramiento bovino ${ }^{7}$. Dicho actor es la empresa IRAC-BIOGEN, ego de la red ganadera. Las actividades de esta empresa se dividen en dos tipos: investigación, capacitación y desarrollo de productos (IRAC), y transferencia y comercialización (BIOGEN). IRAC investiga en el ámbito de la reproducción in vivo e in vitro, el congelamiento de semen y embriones, la superovulación y el sexado de embriones y espermatozoides, entre otras técnicas biotecnológicas. Además, formula protocolos de trabajo para que los productores locales puedan aplicar técnicas de elevada complejidad. Entre sus hitos cabe mencionar el desarrollo de tecnologías de reproducción de bovinos in vitro, que comenzaron a aplicarse por primera vez en la Argentina en 2012. BIOGEN, el pilar comercial de la institución, brinda servicios de transferencia tecnológica, asesoramiento y soluciones a medida para satisfacer las demandas de los productores ganaderos. La exportación de genética es también una de las actividades regulares de la empresa.

En Chile, los productores de recursos naturales que estudiamos son las grandes mineras. La red de conocimiento se reconstruyó en torno a una empresa llamada Aguamarina S. A., que provee servicios biotecnológicos a las empresas mineras y representa el ego de la red minera. Es una empresa de capital nacional, proveedora de soluciones para la minería de mediana y gran escala sobre la base del uso de microorganismos. Uno de sus productos más destacados consiste en una solución biotecnológica para reducir la cantidad de material particulado en suspensión. Asimismo, la empresa desarrolla soluciones y servicios en materia de biolixiviación bacteriana y aplicaciones en las que se utilizan bacterias para combatir el problema de la contaminación (los desechos).

En el Paraguay, los actores seleccionados como sector de recursos naturales son los productores de trigo, quienes se pueden clasificar en tres tipos: i) empresas de gran tamaño, que son productoras y comercializadoras de cereales y oleaginosas; ii) cooperativas de productores agrícolas de tamaño medio, que realizan actividades relacionadas con la comercialización de cereales y oleaginosas, y también producen productos agroindustriales (harinas, aceites y lácteos) e insumos agrícolas (fertilizantes y agroquímicos), y iii) productores agrícolas independientes que no están asociados a las cooperativas.

\footnotetext{
7 Hemos dicho más arriba que el mejoramiento genético se apoya en dos herramientas: la genética cuantitativa y la biotecnología. En nuestro estudio, construimos la red en torno a la segunda, si bien también aparecen actores que utilizan la primera herramienta.
} 
La red estudiada es la que se conformó en torno a un consorcio de actores que llevó adelante un proyecto titulado "Fortalecimiento de la Investigación y Difusión del Cultivo de Trigo en el Paraguay", integrado por la Cámara Paraguaya de Exportadores y Comercializadores de Cereales y Oleaginosas (CAPECO), el Instituto Paraguayo de Tecnología Agraria (IPTA) y el Instituto de Biotecnología Agrícola (INBIO). Este proyecto está orientado al desarrollo de innovaciones y la formación de capacidades tecnológicas en el sector triguero. Su propósito específico es el mejoramiento genético del trigo y la identificación de mejores prácticas agronómicas acordes a las condiciones locales de las diferentes zonas agrícolas del país (Kolhi, Cubilla y Viedma, 2009). El objetivo final del proyecto es aumentar la producción de trigo y su calidad industrial. El consorcio es el ego de la red triguera.

Finalmente, en el Uruguay, dado que el sector forestal está bastante concentrado, tomamos como representante del sector de los recursos naturales a UPM Forestal Oriental, una empresa que integra diferentes eslabones en la producción de celulosa. Nos concentramos en la actividad de la empresa encargada de optimizar la productividad forestal, sobre todo mediante el mejoramiento genético de las variedades. Al ser una multinacional integrada, esta empresa utiliza como fuente principal de conocimiento sus propios viveros y laboratorios. Por lo tanto, a diferencia de las restantes redes, el ego de la red forestal es parte de la misma empresa que produce recursos naturales: el Vivero Santana y el laboratorio de micropropagación.

En el cuadro 1 se sintetizan las características principales del conocimiento del actor que constituye el ego de cada una de las redes, así como el tipo de conocimiento que se produce y difunde dentro de ellas.

Cuadro 1

Actores que constituyen el ego de cada red y tipo de conocimiento que se produce y difunde

\begin{tabular}{|c|c|c|c|c|c|c|}
\hline País & $\begin{array}{l}\text { Conocimiento } \\
\text { de la red }\end{array}$ & Ego & Actividad & $\begin{array}{c}\text { Área de } \\
\text { especialización }\end{array}$ & $\begin{array}{l}\text { Conocimiento } \\
\text { que produce }\end{array}$ & $\begin{array}{c}\text { Hitos de } \\
\text { conocimiento }\end{array}$ \\
\hline 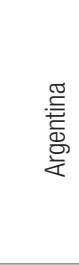 & $\begin{array}{l}\text { Mejoramiento } \\
\text { genético utilizado } \\
\text { en reproducción } \\
\text { de bovinos; red } \\
\text { construida en torno } \\
\text { a una empresa } \\
\text { proveedora de } \\
\text { servicios genéticos }\end{array}$ & IRAC-BIOGEN & $\begin{array}{l}\text { Venta de servicios } \\
\text { Capacitación } \\
\text { Investigación }\end{array}$ & $\begin{array}{l}\text { Desarrollo y } \\
\text { aplicación de } \\
\text { tecnologías } \\
\text { avanzadas de } \\
\text { reproducción animal }\end{array}$ & $\begin{array}{l}\text { Creación de nuevo } \\
\text { conocimiento } \\
\text { científico y } \\
\text { recombinación } \\
\text { de conocimiento } \\
\text { técnico existente } \\
\text { para facilitar } \\
\text { su difusión y } \\
\text { transferencia }\end{array}$ & $\begin{array}{l}\text { Desarrollo de la } \\
\text { tecnología de } \\
\text { producción de } \\
\text { embriones in vitro } \\
\text { en la Argentina }\end{array}$ \\
\hline$\frac{\varrho}{\overline{\frac{D}{U}}}$ & $\begin{array}{l}\text { Soluciones } \\
\text { biotecnológicas en } \\
\text { las que se utilizan } \\
\text { microorganismos } \\
\text { para resolver } \\
\text { problemas de } \\
\text { la minería }\end{array}$ & Aguamarina S. A. & Venta de servicios & $\begin{array}{l}\text { Desarrollo y } \\
\text { aplicación de } \\
\text { tecnologías para } \\
\text { la minería sobre } \\
\text { la base del uso de } \\
\text { microorganismos }\end{array}$ & $\begin{array}{l}\text { Conocimiento } \\
\text { científico y } \\
\text { recombinación } \\
\text { de conocimiento } \\
\text { técnico }\end{array}$ & $\begin{array}{l}\text { Solución } \\
\text { biotecnológica } \\
\text { para reducir la } \\
\text { cantidad de material } \\
\text { particulado en } \\
\text { suspensión } \\
\text { Biolixiviación } \\
\text { bacteriana }\end{array}$ \\
\hline \multirow{3}{*}{ 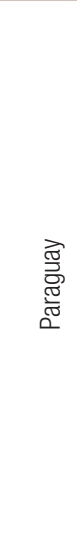 } & \multirow{3}{*}{$\begin{array}{l}\text { Mejoramiento } \\
\text { genético y aumento } \\
\text { de capacidades } \\
\text { en técnicas de } \\
\text { manejo del trigo; } \\
\text { red construida en } \\
\text { torno a un proyecto } \\
\text { específico }\end{array}$} & $\begin{array}{l}\text { Cámara Paraguaya } \\
\text { de Exportadores y } \\
\text { Comercializadores } \\
\text { de Cereales y } \\
\text { Oleaginosas } \\
\text { (CAPECO) }\end{array}$ & $\begin{array}{l}\text { Organización } \\
\text { gremial }\end{array}$ & & Organizacional & \multirow{3}{*}{$\begin{array}{l}\text { Creación de nuevas } \\
\text { variedades de } \\
\text { trigo por región } \\
\text { y mejoras en la } \\
\text { calidad del trigo }\end{array}$} \\
\hline & & $\begin{array}{l}\text { Instituto Paraguayo } \\
\text { de Tecnología } \\
\text { Agraria (IPTA), } \\
\text { asesor científico }\end{array}$ & $\begin{array}{l}\text { Investigación, } \\
\text { transferencia, } \\
\text { extensión y } \\
\text { capacitación }\end{array}$ & $\begin{array}{l}\text { Desarrollo y } \\
\text { aplicación de } \\
\text { tecnologías para } \\
\text { el mejoramiento } \\
\text { genético y el manejo } \\
\text { agronómico de } \\
\text { variedades agrícolas }\end{array}$ & $\begin{array}{l}\text { Recombinación } \\
\text { de conocimiento } \\
\text { técnico }\end{array}$ & \\
\hline & & $\begin{array}{l}\text { Instituto de } \\
\text { Biotecnología } \\
\text { Agrícola (INBIO) }\end{array}$ & $\begin{array}{l}\text { Investigación y } \\
\text { gestión de proyectos }\end{array}$ & $\begin{array}{l}\text { Cabildeo, difusión } \\
\text { y promoción de } \\
\text { la biotecnología } \\
\text { en el Paraguay }\end{array}$ & $\begin{array}{l}\text { Organizacional, } \\
\text { político }\end{array}$ & \\
\hline
\end{tabular}


Cuadro 1 (conclusión)

\begin{tabular}{|c|c|c|c|c|c|c|}
\hline País & $\begin{array}{l}\text { Conocimiento } \\
\text { de la red }\end{array}$ & Ego & Actividad & $\begin{array}{c}\text { Área de } \\
\text { especialización }\end{array}$ & $\begin{array}{l}\text { Conocimiento } \\
\text { que produce }\end{array}$ & $\begin{array}{c}\text { Hitos de } \\
\text { conocimiento }\end{array}$ \\
\hline 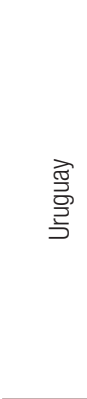 & $\begin{array}{l}\text { Red de } \\
\text { mejoramiento } \\
\text { genético para } \\
\text { aumentar la } \\
\text { productividad } \\
\text { forestal en zonas } \\
\text { frías; red creada } \\
\text { en torno a parte } \\
\text { de la empresa } \\
\text { multinacional UPM } \\
\text { Forestal Oriental }\end{array}$ & $\begin{array}{l}\text { UPM Forestal } \\
\text { Oriental: } \\
\text { laboratorio de } \\
\text { micropropagación } \\
\text { y Vivero Santana }\end{array}$ & $\begin{array}{l}\text { El laboratorio } \\
\text { multiplica clones } \\
\text { provisorios. } \\
\text { El vivero realiza } \\
\text { la propagación } \\
\text { vegetativa de clones } \\
\text { seleccionados de } \\
\text { E. dunnii. Tanto el } \\
\text { laboratorio como } \\
\text { el vivero forman } \\
\text { parte de UPM }\end{array}$ & $\begin{array}{l}\text { Aplicación de } \\
\text { tecnologías de } \\
\text { micropropagación } \\
\text { y propagación } \\
\text { vegetativa }\end{array}$ & $\begin{array}{l}\text { Estandarización } \\
\text { de conocimiento } \\
\text { técnico }\end{array}$ & $\begin{array}{l}\text { Adaptación de la } \\
\text { variedad } E \text {. dunnii } \\
\text { al clima frío. El } \\
\text { vivero se construyó } \\
\text { con una tecnología } \\
\text { innovadora que, } \\
\text { por primera } \\
\text { vez en el país, } \\
\text { permitió adoptar } \\
\text { la propagación } \\
\text { vegetativa (por } \\
\text { estacas) de la } \\
\text { especie E. dunnii } \\
\text { en zonas frías }\end{array}$ \\
\hline
\end{tabular}

Fuente: Elaboración propia.

\section{Fuentes de información}

El trabajo de campo en los cuatro países se llevó a cabo entre diciembre de 2013 y abril de 2014, e incluyó la realización de entrevistas estructuradas y en profundidad. En el cuadro 2 se muestra la cantidad de entrevistas realizadas en cada país, por tipo de actor. Las entrevistas en profundidad permitieron construir el listado inicial de los actores que pertenecían a cada red, delinear el camino para el trabajo subsecuente - sobre todo en cuanto a la selección de los actores que se había de entrevistar - y contextualizar cada caso de estudio.

Cuadro 2

Actores entrevistados en cada país ${ }^{a}$

\begin{tabular}{|c|c|c|c|c|c|c|}
\hline País & $\begin{array}{l}\text { Cantidad de } \\
\text { entrevistas en } \\
\text { profundidad }\end{array}$ & $\begin{array}{c}\text { Cantidad de } \\
\text { entrevistas } \\
\text { semiestructuradas }\end{array}$ & Empresa ego & Tipo de actor entrevistado & $\begin{array}{l}\text { Cantidad } \\
\text { de actores }\end{array}$ & $\begin{array}{l}\text { Período en que } \\
\text { se realizó el } \\
\text { trabajo de campo }\end{array}$ \\
\hline \multirow[b]{3}{*}{ Argentina } & \multirow[b]{3}{*}{4} & \multirow[b]{3}{*}{16} & \multirow[b]{3}{*}{ IRAC-BIOGEN } & Empresa privada & 8 & \multirow{3}{*}{$\begin{array}{l}\text { Desde la última } \\
\text { semana de } \\
\text { diciembre de } \\
2013 \text { hasta } \\
\text { febrero y marzo } \\
\text { de } 2014\end{array}$} \\
\hline & & & & Organismo público de investigación & 2 & \\
\hline & & & & Universidad & 6 & \\
\hline \multirow{5}{*}{ Chile } & \multirow{5}{*}{4} & \multirow{5}{*}{8} & \multirow{5}{*}{ Aguamarina S. A. } & Empresa privada & 4 & \multirow{5}{*}{$\begin{array}{l}\text { Febrero y marzo } \\
\text { de } 2014\end{array}$} \\
\hline & & & & Empresa multinacional & 1 & \\
\hline & & & & Laboratorio privado & 1 & \\
\hline & & & & Asociación & 1 & \\
\hline & & & & Otros & 1 & \\
\hline \multirow{4}{*}{ Paraguay } & \multirow{4}{*}{12} & \multirow{4}{*}{12} & \multirow{4}{*}{$\begin{array}{l}\text { CAPECO- } \\
\text { IPTA-INBIO }\end{array}$} & Empresa privada & 5 & \multirow{4}{*}{$\begin{array}{l}\text { Marzo y abril } \\
\text { de } 2014\end{array}$} \\
\hline & & & & Organismo público de investigación & 1 & \\
\hline & & & & Organización no gubernamental & 1 & \\
\hline & & & & Otros (cooperativas) & 5 & \\
\hline \multirow{6}{*}{ Uruguay } & \multirow{6}{*}{3} & \multirow{6}{*}{17} & \multirow{6}{*}{$\begin{array}{l}\text { UPM Forestal } \\
\text { Oriental }\end{array}$} & Empresa privada & 6 & \multirow{6}{*}{$\begin{array}{l}\text { De enero a } \\
\text { abril de } 2014\end{array}$} \\
\hline & & & & Empresa multinacional & 4 & \\
\hline & & & & Organismo público de investigación & 2 & \\
\hline & & & & Universidad & 2 & \\
\hline & & & & Organización no gubernamental & 1 & \\
\hline & & & & Otros & 2 & \\
\hline
\end{tabular}

Fuente: Elaboración propia.

a En el anexo A se presenta un listado exhaustivo de los actores entrevistados en cada país.

b CAPECO es la Cámara Paraguaya de Exportadores y Comercializadores de Cereales y Oleaginosas; IPTA es el Instituto Paraguayo de Tecnología Agraria, e INBIO es el Instituto de Biotecnología Agrícola. 
El cuestionario se diseñó de modo de captar los distintos tipos de vínculos de conocimiento que cada actor tenía con otros actores del listado que se había elaborado. Se permitió que los actores entrevistados señalaran otros nodos que no se encontraban en el listado, con quienes tenían vínculos de conocimiento. En la Argentina, se reconocieron 135 actores como parte de la red, en Chile, 66, en el Paraguay, 26, y, en el Uruguay, 688.

\section{Métodos de análisis}

En lo que sigue describimos un conjunto de indicadores que utilizamos para evaluar las proposiciones empíricas que se señalaron en la sección II. De conformidad con lo expuesto en dicha sección, agrupamos los indicadores en tres tipos: i) asociados a las capacidades de los actores (vinculados a las proposiciones 1 a 3); ii) asociados a la cohesión de la red (vinculados a las proposiciones 4 a 6) y, iii) asociados a la apertura de la red (vinculados a las proposiciones 7 y 8 ).

En el cuadro 3 se describen los estadísticos que utilizaremos en el análisis y se indica su asociación con las proposiciones empíricas que cada uno ilustra, sea de forma individual o conjunta9 ${ }^{9}$.

Cuadro 3

Indicadores y estadísticos

\begin{tabular}{|c|c|c|c|c|c|c|c|c|}
\hline \multirow[b]{2}{*}{ 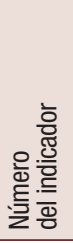 } & \multirow[b]{2}{*}{$\begin{array}{l}\text { Descripción } \\
\text { del indicador }\end{array}$} & \multicolumn{4}{|c|}{ Proposiciones } & \multirow[b]{2}{*}{ Definición y comentarios } & \multirow[b]{2}{*}{$\begin{array}{l}\text { Comparabilidad } \\
\text { entre países }\end{array}$} & \multirow[b]{2}{*}{ Notas sobre comparabilidad } \\
\hline & & $\begin{array}{l}\frac{\mathscr{\pi}}{\pi} \\
\frac{\pi}{0} \\
\frac{\pi}{\pi} \\
\text { त }\end{array}$ & 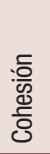 & 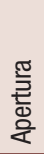 & 造 & & & \\
\hline 1 & $\begin{array}{l}\text { Cantidad } \\
\text { de actores } \\
\text { entrevistados }\end{array}$ & & & & & & Alta & \\
\hline 2 & $\begin{array}{l}\text { Proporción } \\
\text { promedio de } \\
\text { resultados de } \\
\text { conocimiento } \\
\text { por actor }\end{array}$ & $x$ & & $x$ & $\begin{array}{l}1,2 \\
3 \text { y } 7\end{array}$ & $\begin{array}{l}\text { De un listado estándar de } \\
\text { seis resultados posibles: i) } \\
\text { productos, ii) patentes, iii) } \\
\text { otros derechos de propiedad } \\
\text { intelectual, iv) informes de } \\
\text { divulgación, v) extensión } \\
\text { y vi) otros, que incluye } \\
\text { publicaciones, proyectos de } \\
\text { investigación y desarrollo } \\
\text { con financiamiento externo } \\
\text { y otros no incluidos. } \\
\text { Promedio ponderado según } \\
\text { el total de actores presentes } \\
\text { por tipo en cada red. }\end{array}$ & Media & $\begin{array}{l}\text { En el caso de la red } \\
\text { del trigo, se hizo un } \\
\text { relevamiento diferente } \\
\text { de los resultados de la } \\
\text { investigación, lo que } \\
\text { nos obligó a agrupar } \\
\text { las categorías para } \\
\text { que los indicadores } \\
\text { fueran comparables. }\end{array}$ \\
\hline 3 & $\begin{array}{l}\text { Proporción } \\
\text { promedio de } \\
\text { profesionales } \\
\text { por actor }\end{array}$ & $x$ & & $x$ & $\begin{array}{l}1,2 \\
3 \text { y } 8\end{array}$ & $\begin{array}{l}\text { Promedio de la participación } \\
\text { de profesionales entre los } \\
\text { ocupados en cada actor, } \\
\text { ponderado según el total } \\
\text { de actores presentes } \\
\text { por tipo en cada red. }\end{array}$ & Alta & \\
\hline 4 & $\begin{array}{l}\text { Capacidades } \\
\text { en los vínculos: } \\
\text { relación entre } \\
\text { exploración } \\
\text { y difusión }\end{array}$ & $x$ & & & 1 & $\begin{array}{l}\text { Díadas (vínculos entre } \\
\text { dos actores) con flujos } \\
\text { de conocimiento nuevo } \\
\text { y díadas con flujos de } \\
\text { conocimiento existente. }\end{array}$ & Media & $\begin{array}{l}\text { En la red minera se tuvieron } \\
\text { en cuenta las actividades } \\
\text { del actor central, pero no } \\
\text { las enfocadas únicamente } \\
\text { en la actividad minera. }\end{array}$ \\
\hline 5 & $\begin{array}{l}\text { Centralidad } \\
\text { (cercanía de } \\
\text { salida) }\end{array}$ & $x$ & & & 3 & $\begin{array}{l}\text { Cantidad mínima de } \\
\text { pasos necesarios para } \\
\text { Ilegar desde cada actor } \\
\text { a todos los restantes. }\end{array}$ & Media & \\
\hline
\end{tabular}

8 En el Paraguay, el número total de actores identificados es mucho menor porque se trata exclusivamente de actores vinculados a un proyecto específico.

9 En relación con el análisis empírico de las redes, se ha utilizado el paquete "igraph" (Csardi y Nepusz, 2006), implementado en el lenguaje "R" (R Development Core Team, 2014). 
Cuadro 3 (conclusión)

\begin{tabular}{|c|c|c|c|c|c|c|c|c|}
\hline \multirow[b]{2}{*}{ 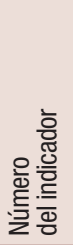 } & \multirow[b]{2}{*}{$\begin{array}{l}\text { Descripción } \\
\text { del indicador }\end{array}$} & \multicolumn{4}{|c|}{ Proposiciones } & \multirow[b]{2}{*}{ Definición y comentarios } & \multirow[b]{2}{*}{$\begin{array}{l}\text { Comparabilidad } \\
\text { entre países }\end{array}$} & \multirow[b]{2}{*}{ Notas sobre comparabilidad } \\
\hline & & $\begin{array}{l}\frac{\mathscr{I}}{0} \\
\frac{\pi}{0} \\
\frac{\pi}{0} \\
\frac{\pi}{0}\end{array}$ & $\begin{array}{l}\text { 응 } \\
\text { 융 }\end{array}$ & 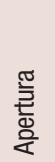 & $\begin{array}{l}\text { 잏 } \\
\text { 穵 }\end{array}$ & & & \\
\hline 7 & Transitividad & & $x$ & & 6 & $\begin{array}{l}\text { Probabilidad de que } \\
\text { dos actores conectados } \\
\text { a un tercero estén } \\
\text { conectados entre sí. }\end{array}$ & Media & \\
\hline 8 & $\begin{array}{l}\text { Reciprocidad: } \\
\text { porcentaje } \\
\text { de díadas } \\
\text { bidireccionales }\end{array}$ & & $x$ & & 5 & $\begin{array}{l}\text { Díadas (vínculos entre } \\
\text { dos actores) con flujos } \\
\text { de conocimiento mutuo o } \\
\text { bidireccional, como proporción } \\
\text { del total de díadas existentes } \\
\text { (mutuas + asimétricas). }\end{array}$ & Media & \\
\hline 9 & $\begin{array}{l}\text { Reciprocidad: } \\
\text { porcentaje } \\
\text { de díadas } \\
\text { unidireccionales }\end{array}$ & & $x$ & & 5 & $\begin{array}{l}\text { Díadas (vínculos entre } \\
\text { dos actores) con flujos de } \\
\text { conocimiento asimétrico } \\
0 \text { unidireccional, como } \\
\text { proporción del total de } \\
\text { díadas existentes (mutuas } \\
+ \text { asimétricas). }\end{array}$ & Media & \\
\hline 10 & Apertura & & & $x$ & 7 y 8 & $\begin{array}{l}\text { En cada red hay un grupo de } \\
\text { actores "núcleo" compuesto } \\
\text { por los productores de } \\
\text { recursos naturales y otros } \\
\text { actores que se vinculan } \\
\text { con ellos de forma directa, } \\
\text { frecuente e importante. Con } \\
\text { el indicador de apertura } \\
\text { se evalúa la proporción } \\
\text { de actores (por tipo) que } \\
\text { quedan fuera del núcleo, } \\
\text { en relación con aquellos } \\
\text { que quedan dentro de él. }\end{array}$ & Media & $\begin{array}{l}\text { En el caso de la red } \\
\text { minera, las entrevistas } \\
\text { se concentraron en } \\
\text { actores que no eran los } \\
\text { productores de recursos } \\
\text { naturales y, por ende, } \\
\text { los valores de apertura } \\
\text { resultantes serán elevados. }\end{array}$ \\
\hline
\end{tabular}

Fuente: Elaboración propia.

\section{a) Indicadores asociados a las capacidades}

Para evaluar las capacidades de los actores de las redes utilizamos dos indicadores claves. Por un lado, la cantidad de resultados de conocimiento producidos por cada actor (indicador 2) y, por otro, la dotación de recursos humanos calificados (profesionales) (indicador 3). En la construcción de estos indicadores, imputamos valores a los actores que, si bien fueron identificados en la red, no fueron entrevistados. La imputación se realizó según el tipo de actor, tomando los datos que proporcionaron los actores entrevistados.

Estos dos indicadores de capacidades se calcularon, a su vez, respecto de distintos grupos. Por un lado, dado que en la literatura se determinó que una condición para la socialización y difusión del conocimiento es que la mayor parte de los actores de la red tuvieran una capacidad mínima relativamente alta, medimos las capacidades de los actores que se encuentran en el percentil 25 (sobre la base del indicador 3).

Además, de acuerdo con la literatura, las capacidades de los actores que ocupan un lugar central en la red son de particular relevancia. Para evaluar esta característica, combinamos la información sobre capacidades (indicadores 2 y 3 ) y sobre centralidad (cercanía de salida) (indicador 5). La cercanía de salida mide la cantidad mínima de pasos necesarios para llegar desde cada actor a todos los restantes, teniendo en cuenta la direccionalidad del flujo de conocimiento (solo salida). La medida se basa en la idea de que los actores que pueden interactuar más rápidamente con el resto 
son más centrales (Wasserman y Faust, 1998). Así definido, este indicador, que solo se pudo calcular en relación con los actores que entrevistamos (no hubo imputaciones), se dividió en tres grupos que permitían identificar actores de centralidad alta, media y baja, tomando en cuenta el percentil $(1 / 3)$ y el percentil (2/3) como puntos de corte en cada caso de estudio ${ }^{10}$. De esta forma, luego evaluamos las capacidades de cada uno de estos grupos, esperando que los actores centrales fueran especialmente capaces.

Otra medida que utilizamos en relación con las capacidades de los actores está vinculada al tipo de conocimiento que se difunde entre ellos. Proponemos un indicador que mide si los vínculos entre los actores se basan en la difusión de conocimiento existente o en la exploración de nuevo conocimiento (indicador 4). Los vínculos de creación de conocimiento incluyen los intercambios realizados en el marco de acuerdos de investigación y desarrollo o de contratos de investigación; los de conocimiento existente son los intercambios realizados mediante acuerdos de prestación de servicios, asistencia técnica, transferencia de tecnología, ensayos y experimentación, capacitación y extensión. Entendemos que los vínculos que involucran creación de conocimiento nuevo requieren capacidades más sofisticadas. Esta medida es un buen complemento de las anteriores, ya que permite capturar capacidades que no se encuentran formalizadas en títulos universitarios o materializadas en productos de investigación y desarrollo ${ }^{11}$.

\section{b) Indicadores asociados a la cohesión}

De acuerdo con la literatura, un alto nivel de aglomeración garantiza una difusión amplia y rápida del conocimiento. Medimos el nivel de aglomeración de las redes con un indicador de densidad de la red (indicador 6). Este se define como la proporción de vínculos que efectivamente existen en la red (sin importar su direccionalidad) respecto del total de vínculos posibles (si $n$ es la cantidad de nodos de la red, la máxima cantidad de vínculos posibles es el combinatorio de $n$ tomado de a dos, igual a $n(n-1) / 2)$.

Complementamos la medida de aglomeración con una de incrustación estructural a partir de un índice de transitividad, definido como la probabilidad de que dos actores que están vinculados a un tercero estén vinculados entre sí (indicador 7). Este indicador mide el surgimiento de "triángulos" en la red.

Incorporamos también un indicador de reciprocidad de los intercambios mediante un censo de díadas. Se llama díada a cualquier par de nodos. Pueden existir díadas "mutuas", cuando se produce un intercambio bidireccional, "asimétricas", cuando el intercambio es unidireccional, y "nulas", cuando no existe intercambio (Wasserman y Faust, 1998). El censo de díadas es un recuento de todos los tipos de díadas. A partir de esto, calculamos la proporción de vínculos mutuos y asimétricos como porcentaje del total de vínculos bidireccionales y unidireccionales (es decir, díadas mutuas y asimétricas) (indicadores 8 y 9).

Finalmente, también calculamos los indicadores de cohesión respecto de subredes definidas según el tipo de conocimiento que circula, ya sea nuevo o existente, según se explicó en relación con los indicadores asociados a las capacidades.

Todos los indicadores de cohesión, y también los de apertura que se explican a continuación, se construyeron a partir de los datos de los actores que entrevistamos (es decir, no se realizaron imputaciones).

\footnotetext{
${ }^{10}$ Como los valores de la cercanía de salida se repiten entre los actores de cada país, la distribución de actores por categoría no es necesariamente pareja.

${ }^{11}$ En la red de conocimiento existente del trigo también se incorporaron los días de campo, que se asignaron a la categoría "Otros".
} 


\section{c) Indicadores asociados a la apertura}

Para analizar el nivel de apertura de cada red, construimos un indicador que llamamos "de migración". Con ese fin, definimos un núcleo de actores de cada red, conformado por el grupo de productores de recursos naturales y los actores que poseen vínculos más frecuentes, importantes y directos con ellos; luego, evaluamos cómo la red se fue ampliando más allá del área de influencia de la producción de recursos naturales estudiada en cada caso (indicador 10). Este cálculo no se pudo llevar a cabo en relación con la red minera, porque allí no se hicieron entrevistas a los productores mineros. En las otras redes, evaluamos la proporción de actores que se encuentran dentro y fuera del núcleo, así como su composición por tipo.

\section{Resultados empíricos}

En esta sección, presentamos un análisis conjunto de las cuatro redes de recursos naturales estudiadas: la red ganadera, en la Argentina; la red minera, en Chile; la red triguera, en el Paraguay, y la red forestal, en el Uruguay. El objetivo de la sección es explorar hasta qué punto estas redes, que se originan como respuesta a las necesidades de conocimiento de actores que producen recursos naturales, tienen potencial para crear y difundir conocimiento y, eventualmente, extender las aplicaciones de ese conocimiento hacia otras actividades productivas. La sección está organizada siguiendo el orden de las proposiciones que se mencionaron en la sección II. Por consiguiente, en primer lugar, analizamos las capacidades, luego, la cohesión y, por último, la apertura.

\section{Las capacidades de los actores de las redes}

Los distintos indicadores que utilizamos para medir las capacidades muestran que las redes tienen diferentes características. En la red minera, la mayor parte de los actores entrevistados son empresas privadas que tienen vínculos comerciales con una empresa proveedora de servicios biotecnológicos para la minería. Como se ve en el cuadro 4, los indicadores seleccionados ponen de manifiesto que los actores individuales de esta red en general tienen capacidades elevadas. Además, la distribución de las capacidades parece bastante equitativa y el mínimo de las capacidades de todos los actores participantes es alto: el 25\% de los actores que menos capacidades tiene presenta una ratio superior al 83\% entre el número de profesionales y el número de ocupados (véase el gráfico 1). Es decir, se trata de una red que, en términos de capacidades, tiene un muy buen pronóstico relativo a la difusión y creación de conocimiento.

Cuadro 4

Capacidad promedio de cada red sobre la base de los actores entrevistados

(En porcentajes)

\begin{tabular}{|c|c|c|c|c|c|c|}
\hline & \multirow{3}{*}{$\begin{array}{c}\text { Cantidad } \\
\text { de actores } \\
\text { entrevistados }\end{array}$} & \multirow{3}{*}{$\begin{array}{c}\text { Proporción promedio } \\
\text { de resultados } \\
\text { de conocimiento } \\
\text { por actor }{ }^{\mathrm{b}}\end{array}$} & \multicolumn{4}{|c|}{ Profesionales } \\
\hline & & & \multirow[b]{2}{*}{$\begin{array}{l}\text { Proporción en cada } \\
\text { red entrevistada }\end{array}$} & \multicolumn{3}{|c|}{ Proporción por actor ${ }^{a}$} \\
\hline & & & & Promedio & Percentil 25 & $\begin{array}{l}\text { Coeficiente } \\
\text { de variación }\end{array}$ \\
\hline Red ganadera & 16 & 59,3 & 53,2 & 70,3 & 25,4 & 43,3 \\
\hline Red minera & 8 & 58,6 & 59,4 & 86,8 & 83,6 & 27,2 \\
\hline Red triguera ${ }^{\mathrm{C}}$ & 12 & 53,0 & 15,6 & 18,0 & 8,4 & 67,0 \\
\hline Red forestal & 17 & 42,3 & 31,3 & 62,9 & 46,8 & 41,3 \\
\hline
\end{tabular}

Fuente: Elaboración propia.

a Promedio expandido por tipo de actor: en la red ganadera, a 114 nodos; en la red minera, a 36; en la red triguera, a 18, y, en la red forestal, a 58, utilizando las medidas obtenidas de los entrevistados en cada caso.

b Se consideran seis categorías de resultados de conocimiento.

c En la red triguera se dispone de información sobre los recursos humanos de 11 de los entrevistados. 
Gráfico 1

Distribución de la proporción de profesionales en las distintas redes

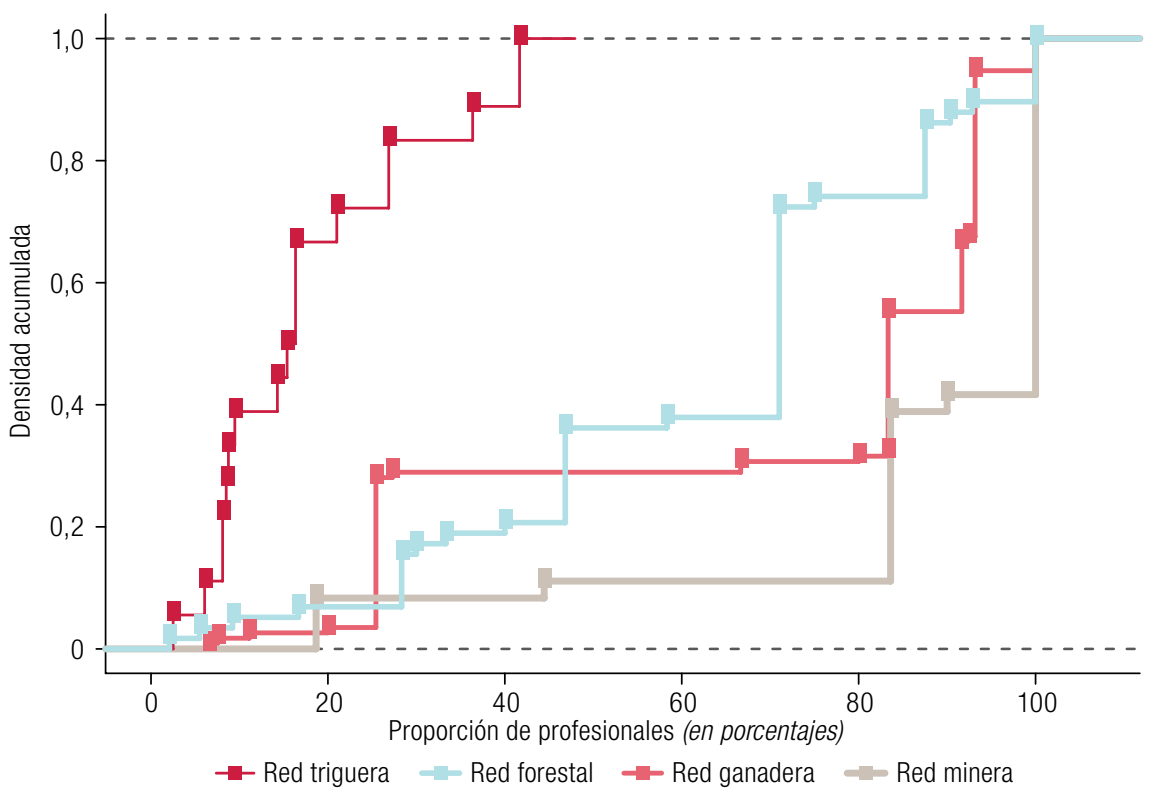

Fuente: Elaboración propia.

La red ganadera es una red cuyos recursos humanos tienen un alto nivel de formación. En promedio, el $70 \%$ de los ocupados en cada actor es profesional, si bien el coeficiente de variación es del 43\%, es decir, las capacidades están bastante dispersas en el interior de la red. Esto también implica que el mínimo de las capacidades en la red es relativamente bajo. Así, en el $25 \%$ integrado por los actores que menos capacidades tienen apenas se alcanza una ratio del $25 \%$ entre el número de profesionales y el de ocupados. Aunque no podemos establecer cuál es el umbral mínimo de capacidades, estas dos últimas características podrían reducir el potencial de la red para difundir el conocimiento en el plano interno.

En la red forestal, la proporción de profesionales en el total de ocupados por actor es elevada (63\%) y las capacidades mínimas tienden a ser altas: en el 25\% compuesto por los actores que menos capacidades tienen, la proporción de profesionales respecto del total de ocupados asciende al $47 \%$. Esto implica que existe una masa crítica de conocimiento en la red que es lo suficientemente alta como para que el conocimiento científico pueda circular con facilidad. Sin embargo, la distribución de capacidades dentro de la red no es buena.

Por último, la red triguera presenta valores relativamente bajos en cuanto a los indicadores de capacidad, sobre todo con respecto al porcentaje de profesionales entre los ocupados de cada actor. Además, la distribución de capacidades tampoco es buena. De hecho, en el gráfico 1 se observa que, entre los recursos humanos de más del $60 \%$ de los actores entrevistados, menos del $20 \%$ son profesionales. Es de esperar que estas características no favorezcan la difusión del conocimiento, ni dentro ni fuera de la red.

En el cuadro 5 se muestran los mismos indicadores de capacidad, pero en relación con los actores que desempeñan un papel central en la difusión de conocimiento de la red. Cuanto más altas sean las capacidades de este grupo, mejores serán los pronósticos relativos a la difusión y creación de conocimiento. La relación directa entre centralidad y capacidades parecería estar presente en todas las redes excepto en la forestal. Esto sugiere que las redes ganadera, minera y triguera tienen un buen potencial para la circulación de conocimiento, ya que, en las tres, los actores centrales tienen capacidades elevadas. 


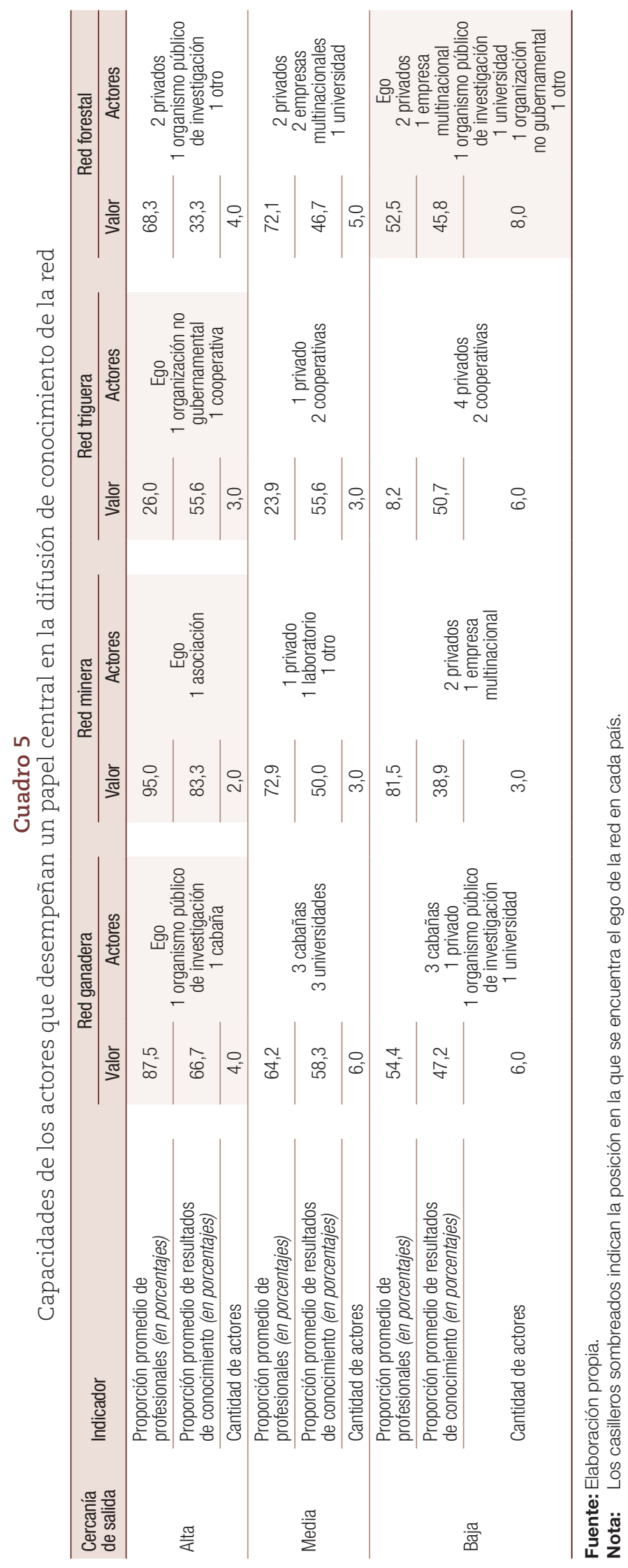


También resulta interesante que, en todos los casos excepto en la red forestal, el actor ego de la red se encuentra en el grupo de actores que tienen una centralidad elevada. Si bien esto en parte responde a la propia reconstrucción de la red, ya que fue el propio ego quien originalmente informó quiénes eran los actores participantes, el hecho de medir la centralidad como cercanía de salida matiza el sesgo de centralidad por diseño, ya que esta se mide en términos de emisión o salida de conocimiento.

El ego de la red forestal es la subsidiaria de una empresa multinacional y es receptor neto de conocimiento. Como se pudo corroborar durante el trabajo de campo, este actor tiene una actitud cuidadosa y procura evitar que se difunda el conocimiento sobre el mejoramiento genético que la empresa considera su principal fuente de competitividad.

Por último, en el cuadro 6 se muestra el tipo de vínculo que corresponde a cada díada. Lo primero que llama la atención, si miramos la cuarta columna, es que en ninguna de las redes la relación entre la exploración y la difusión es superior al 100\%, lo que indica que, en todas ellas, la principal actividad es la de difusión de conocimiento existente. Sin embargo, hay diferencias entre las distintas redes.

Cuadro 6

Distribución de los vínculos de conocimiento nuevo y los de conocimiento existente por red

\begin{tabular}{|c|c|c|c|c|c|}
\hline & & & Vínculos & & \\
\hline & & Totales & $\begin{array}{l}\text { Conocimiento } \\
\text { nuevo }\end{array}$ & $\begin{array}{l}\text { Conocimiento } \\
\text { existente }\end{array}$ & exploración y difusión \\
\hline Bed ganadera & Cantidad & 52,0 & 15,0 & 37,0 & 405 \\
\hline Reu gallauera & Porcentaje del total & 100,0 & 28,8 & 71,2 & 40,0 \\
\hline & Cantidad & 19,0 & 9,0 & 10,0 & an \\
\hline rea minterd & Porcentaje del total & 100,0 & 47,4 & 52,6 & 90,0 \\
\hline Red triauera & Cantidad & 36,0 & 1,0 & 35,0 & 29 \\
\hline Rea iniguera & Porcentaje del total & 100,0 & 2,8 & 97,2 & 2,9 \\
\hline Red forectal & Cantidad & 42,0 & 16,0 & 26,0 & 615 \\
\hline Red torestal & Porcentaje del total & 100,0 & 38,1 & 61,9 & bl,5 \\
\hline
\end{tabular}

Fuente: Elaboración propia.

En suma, el análisis de las capacidades parece indicar que, por distintos motivos, en todas las redes existe buen potencial para la difusión de conocimiento. Si bien en la red triguera las capacidades son escasas en términos absolutos y se explora menos, la capacidad se encuentra bien distribuida en el interior de la red y las capacidades de los actores centrales son mayores que las del resto de los actores.

\section{La cohesión de las redes}

En el cuadro 7 presentamos los indicadores de cohesión de todas las redes y también de las subredes definidas según el tipo de conocimiento que circula. Encontramos que la red triguera es una red de alta densidad, reciprocidad y transitividad. En esta red se intercambia sobre todo conocimiento existente. Como se puede ver en la segunda columna, solo dos actores participan en la red de creación de nuevo conocimiento. Esto sugiere un alto potencial para la difusión de conocimiento entre los actores de la red, si bien el nivel bajo de capacidad presente en ella de alguna forma relativiza este potencial.

En una situación contraria se encuentran las redes ganadera, minera y forestal, que muestran un alto nivel de capacidad, pero uno reducido de cohesión con respecto a todos los indicadores utilizados (con excepción del indicador de reciprocidad en el caso de la red minera). Los indicadores de reciprocidad de la red forestal tienen valores particularmente bajos. 
Cuadro 7

Estructura de las redes: densidad, transitividad y reciprocidad (En porcentajes)

\begin{tabular}{|c|c|c|c|c|}
\hline & & Red completa & $\begin{array}{l}\text { Red de conocimiento } \\
\text { nuevo }\end{array}$ & $\begin{array}{l}\text { Red de conocimiento } \\
\text { existente }\end{array}$ \\
\hline \multirow{5}{*}{ Red ganadera } & Densidad & 40,0 & 19,2 & 30,8 \\
\hline & Transitividad & 43,9 & 25,0 & 39,6 \\
\hline & Reciprocidad (bidireccional) & 83,3 & 93,3 & 64,9 \\
\hline & Reciprocidad (unidireccional) & 16,7 & 6,7 & 35,1 \\
\hline & Cantidad de actores & 16,0 & 13,0 & 16,0 \\
\hline \multirow{5}{*}{ Red minera } & Densidad & 39,3 & 32,1 & 35,7 \\
\hline & Transitividad & 44,1 & 27,3 & 40,0 \\
\hline & Reciprocidad (bidireccional) & 100,0 & 100,0 & 90,0 \\
\hline & Reciprocidad (unidireccional) & 0,0 & 0,0 & 10,0 \\
\hline & Cantidad de actores & 8,0 & 8,0 & 8,0 \\
\hline \multirow{5}{*}{ Red triguera } & Densidad & 65,2 & 100,0 & 53,0 \\
\hline & Transitividad & 75,7 & 0,0 & 62,3 \\
\hline & Reciprocidad (bidireccional) & 93,0 & 100,0 & 82,9 \\
\hline & Reciprocidad (unidireccional) & 7,0 & 0,0 & 17,1 \\
\hline & Cantidad de actores & 12,0 & 2,0 & 12,0 \\
\hline \multirow{5}{*}{ Red forestal } & Densidad & 32,4 & 24,2 & 24,8 \\
\hline & Transitividad & 44,0 & 38,9 & 20,2 \\
\hline & Reciprocidad (bidireccional) & 54,5 & 68,8 & 19,2 \\
\hline & Reciprocidad (unidireccional) & 45,5 & 31,3 & 80,8 \\
\hline & Cantidad de actores & 17,0 & 12,0 & 15,0 \\
\hline
\end{tabular}

Fuente: Elaboración propia.

Nota: Cuando el número de actores en la red es elevado, los indicadores utilizados toman valores extremos y su interpretación no resulta totalmente confiable. Esto sucede en el caso de la red de conocimiento nuevo de la red triguera.

En la red ganadera, llama la atención el hecho de que la densidad en la subred de conocimiento existente sea considerablemente mayor que en la de conocimiento nuevo. En los casos de las redes forestal y minera, no existe una diferencia tan marcada entre las subredes.

En suma, a la inversa de lo que había resultado del análisis de las capacidades en la sección precedente, encontramos que la red triguera es la que tiene una estructura favorable a la creación y difusión de conocimiento. El caso opuesto lo representaría la red forestal, ya que la reciprocidad y la densidad son extremadamente bajas. Esto no resulta del todo sorprendente, ya que, mientras que la red triguera se creó a partir de un consorcio de actores con un fin particular, la forestal se construyó a partir de la subsidiaria de una multinacional, actor que suele tener una inclinación menor a socializar el conocimiento.

\section{La apertura de las redes}

Según la literatura, las redes que tienen un mayor nivel de apertura tienen más posibilidades de acceder a una diversidad de conocimiento, profundizar sus capacidades y acelerar de esta manera su creatividad para crear nuevo conocimiento. En los cuadros 8,9 y 10 se muestran los resultados del análisis. 
Cuadro 8

Migración en la red ganadera

\begin{tabular}{lccc}
\hline & \multicolumn{2}{c}{ Red ganadera } \\
\cline { 2 - 3 } & Núcleo & Migración & $\begin{array}{c}\text { Ratio entre la cantidad de migración } \\
\text { y la cantidad del núcleo } \\
\text { (en porcentajes) }\end{array}$ \\
\cline { 2 - 3 } & Cantidad & Cantidad & \\
\hline Cabañas & 23 & 0 & - \\
\hline Otros privados & 4 & 12 & 300 \\
\hline Organismos públicos de investigación & 3 & 7 & 233 \\
\hline Universidades & 5 & 22 & 440 \\
\hline Organismos gubernamentales & 1 & 0 & 0 \\
\hline Asociaciones & 4 & 7 & 175 \\
\hline Total & 40 & 48 & 120 \\
\hline
\end{tabular}

Fuente: Elaboración propia.

Cuadro 9

Migración en la red triguera

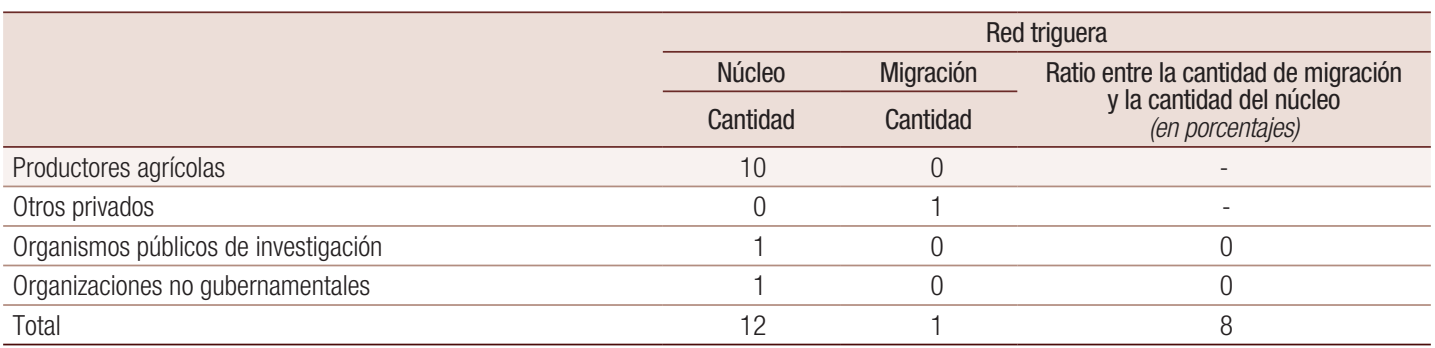

Fuente: Elaboración propia.

Cuadro 10

Migración en la red forestal

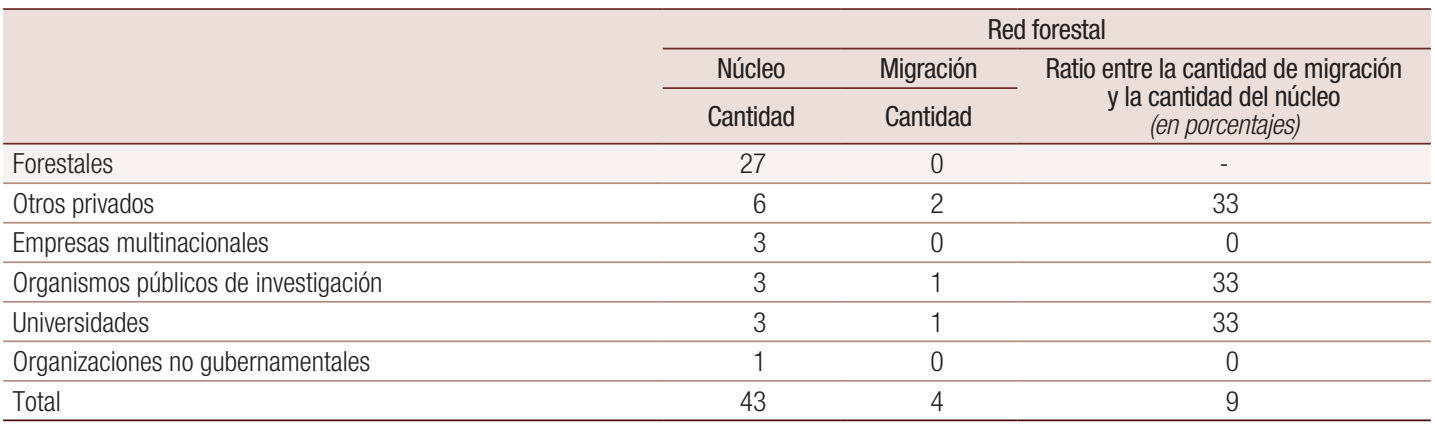

Fuente: Elaboración propia.

La red ganadera es la única que tiene un nivel elevado de apertura: más del 50\% de los actores estudiados no son empresas productoras de recursos naturales ni tienen vínculos directos con ellas del tipo frecuente e importante como los que se evalúan en este indicador. La migración total en esta red (el crecimiento de la cantidad de actores) es de un 120\%. En la red triguera, este valor es del $8 \%$ y, en la red forestal, del 9\%.

Esto indica que la red ganadera tiene, en principio, una alta capacidad de captar conocimiento que viene desde fuera de la red núcleo (productores de recursos naturales y sus vínculos directos), y de difundir conocimiento de la red hacia afuera. En la red forestal y la red triguera, por el contrario, al parecer no es habitual que se reciba y difunda conocimiento más allá de la red núcleo. En el caso de la red triguera, esta situación de poca apertura podría requerir atención, porque es una red con capacidades relativamente bajas que, sin apertura, podría enfrentar un mayor riesgo de encajonamiento tecnológico. Sin embargo, hay que tener en cuenta que esta red, a diferencia de 
las otras tres, se estudió en relación con un proyecto específico, lo que necesariamente sesga hacia abajo el indicador de apertura. En este sentido, es muy probable que los actores de la red tengan vínculos con otros actores en otros proyectos de investigación que no se analizaron.

En términos de apertura de la red, también planteamos que la efectividad en cuanto a la creación y difusión de conocimiento estaría asociada con el hecho de que los actores que no pertenecen al núcleo tuvieran capacidades relativamente más elevadas. Para evaluar esta característica, estimamos la proporción de profesionales y la proporción de resultados de conocimiento (indicadores 2 y 3 del cuadro 3) en relación con los grupos de actores del núcleo y los de la migración; los resultados se presentan en el cuadro 11. Alí se puede observar que la red ganadera presenta buenos indicadores en este sentido, con un porcentaje promedio de profesionales fuera del núcleo que casi duplica al que se observa dentro de él. También se registra una mayor proporción promedio de resultados de conocimiento entre los actores pertenecientes a la migración.

Cuadro 11

Capacidades de los actores del núcleo y la migración

(En porcentajes)

\begin{tabular}{llrr}
\hline & \multicolumn{1}{c}{ Estimación de capacidades } & Núcleo & Migración \\
\hline \multirow{2}{*}{ Red ganadera } & Proporción de profesionales & 46,9 & 90,5 \\
\cline { 2 - 4 } & Proporción de resultados de conocimiento & 49,1 & 67,3 \\
\hline \multirow{2}{*}{ Red triguera } & Proporción de profesionales & 16,5 & 8,5 \\
\cline { 2 - 4 } & Proporción de resultados de conocimiento & 54,5 & 33,3 \\
\hline \multirow{2}{*}{ Red forestal } & Proporción de profesionales & 60,0 & 55,0 \\
\cline { 2 - 4 } & Proporción de resultados de conocimiento & 40,9 & 47,3 \\
\hline
\end{tabular}

Fuente: Elaboración propia.

Nota: La estimación se basa en la expansión de los datos de los entrevistados, por tipo de actor, al resto de los nodos. Con ese fin, se utilizó el promedio de la proporción de profesionales y de resultados de conocimiento. Hay casos en que no se entrevistó a ciertos tipos de actores que pueden pertenecer al núcleo o a la migración; en esos casos, el dato relativo a las capacidades queda faltante (missing).

En la red triguera, las estimaciones arrojan resultados diametralmente opuestos: la capacidad en la migración es considerablemente menor que dentro del núcleo. Sin embargo, en este caso particular existe solo un actor fuera del núcleo, y debe recordarse que la red se construyó en torno a un proyecto particular, por lo que se deben tener en cuenta las consideraciones del caso que ya se han mencionado.

Por último, en el caso de la red forestal, la capacidad promedio de los actores que se encuentran dentro y fuera del núcleo es similar. Esto coincide con la interpretación de una red que se cierra en parte debido al celo sobre los resultados de conocimiento y al resguardo de estos como fuente de competitividad. En este sentido, tanto los actores del núcleo como los de la migración poseen capacidades elevadas.

\section{Conclusiones e implicaciones en materia de política}

Las actividades relacionadas con los recursos naturales han sido y siguen siendo controversiales. Algunos sostienen que son perjudiciales para los países, porque crean problemas ambientales, institucionales y económicos. Muchos, en cambio, sostienen que el efecto que estas actividades tienen sobre el desarrollo depende en gran medida del conjunto de instituciones que se empleen para organizarlas dentro de cada país. Un argumento que ha ganado importancia recientemente es que, más allá de esta discusión, las condiciones tecnológicas y de mercado actuales han cambiado, y existen nuevas 
oportunidades para sacar provecho de los recursos naturales en la medida en que estas actividades se vuelvan más intensivas en conocimiento, tengan un mayor potencial para incentivar otras actividades de conocimiento y presenten menos posibilidades de afectar el medio ambiente.

En este trabajo, estudiamos en profundidad cuatro redes de colaboración que se han establecido a partir de las necesidades de conocimiento científico de cuatro sectores de recursos naturales seleccionados en cuatro países. Escogimos sectores que tienen importancia para cada una de las economías estudiadas: el sector ganadero, en la Argentina; el minero, en Chile; el agrícola, en el Paraguay, y el forestal, en el Uruguay. También elegimos los casos con el propósito de captar una diversidad de actores que ocupan el lugar central en cada red. Así, en el caso de la Argentina, dicho actor central es una empresa nacional proveedora de servicios biotecnológicos para la ganadería. Este es también el caso de Chile, solo que la empresa presta servicios para la minería. En el Paraguay, en cambio, el actor central es un consorcio público-privado y, en el Uruguay, un laboratorio y un vivero integrados a una empresa multinacional.

El estudio es de carácter exploratorio. No existen muchos antecedentes en la literatura en los que se estudien redes de conocimiento científico asociado a la producción de recursos naturales y no conocemos antecedentes de estudios comparativos en América Latina. En todas las redes elegidas, la biotecnología desempeña un papel central como campo de investigación científica que tiene el potencial de nutrir las innovaciones, aunque en la red triguera el papel efectivo de la biotecnología es, por ahora, más incipiente. La evidencia empírica recolectada no fue exhaustiva, ya que entrevistamos solo a un grupo de actores pertenecientes a cada red. Las conclusiones presentadas, por lo tanto, deben considerarse teniendo en cuenta las dificultades que surgen cuando se comparan casos de estudio de diversa índole y las limitaciones relativas a la representatividad de la información que se recolectó para cada caso.

El análisis empírico, sin embargo, arroja algunos indicios interesantes que hacen posible una primera aproximación al problema objeto de investigación. También nos permite formular algunas preguntas nuevas de relevancia que se podrían investigar en el futuro.

En nuestro estudio se pudo determinar que, efectivamente, en las actividades vinculadas con los recursos naturales se utiliza conocimiento científico, que este es importante en su operación y que estas necesidades incentivan el desarrollo de redes de conocimiento de diferente naturaleza. Identificamos una diversidad de actores que participan en cada red, a saber: universidades, organismos públicos de investigación, actores privados, institutos privados de investigación y otros. También registramos diferentes tipos de acuerdos de intercambio de conocimiento (investigación y desarrollo, capacitación, asistencia técnica, ensayos y experimentación, entre otros).

Las redes de conocimiento estudiadas presentan algunas características bien diferenciadas, que permiten reflexionar acerca de su potencial importancia para crear y difundir conocimiento.

En primer lugar, el análisis de las capacidades de los actores nos muestra que, si bien todas las redes son diferentes, en cada una de ellas hay indicadores que ponen de relieve cierto potencial para difundir o crear conocimiento nuevo. A partir del análisis de la literatura, establecimos tres proposiciones empíricas asociadas a las capacidades que, de cumplirse, incentivarían el buen funcionamiento de la red en términos de creación y difusión de conocimiento: i) que el promedio de las capacidades fuera alto; ii) que el mínimo de las capacidades también lo fuera, y iii) que también fueran elevadas las capacidades de los actores que desempeñan un papel central en la red. Si bien las capacidades promedio y las capacidades mínimas de la red triguera son muy bajas, el actor central de esa red es el que tiene mayores capacidades y puede, por lo tanto, contribuir a la difusión de conocimiento entre los demás actores. En las otras tres redes, las capacidades promedio de los actores participantes son, al menos, moderadamente altas. En la red ganadera no se cumple la condición de que el mínimo sea elevado, pero sí que el actor central tenga las capacidades superiores. En la red forestal se da la situación inversa y, en la red minera, se cumplen todas las condiciones asociadas a las capacidades. 
En segundo lugar, se evaluó el nivel de cohesión de las redes de recursos naturales mediante indicadores de densidad, transitividad y reciprocidad. Los resultados muestran que las redes son heterogéneas, pero en todas encontramos algunas características que en la literatura se señalan como promisorias. Las redes ganadera, minera y triguera presentan un nivel muy alto de reciprocidad, y este indicador también es moderadamente alto en la red forestal. En cambio, solo en la red triguera hay también un nivel elevado de transitividad y densidad. Esto indica que, si bien el intercambio entre los actores conectados tiende a ser simétrico, lo que sin dudas favorece la cohesión y la confianza entre ellos, las redes como un todo todavía tienen camino por recorrer en este sentido.

Por último, en tercer lugar, analizamos el nivel de apertura de las redes. La red ganadera mostró un alto nivel de apertura: esta red se amplía en un 120\% fuera del núcleo de los recursos naturales. En las otras redes, en cambio, el nivel de apertura es bajo: el 8\% en la red triguera (cifra afectada en parte por el diseño del estudio), y el $9 \%$ en la forestal. No se pudo hacer este cálculo en relación con la red minera, debido a que no se entrevistaron productores mineros.

En suma, en nuestro estudio se encontró evidencia sólida de que existen redes asociadas a la innovación en el ámbito de los recursos naturales, en las que participan una diversidad de actores que tienen distintas capacidades. Estas redes pueden servir para difundir conocimiento existente y también para crear conocimiento nuevo o nuevas aplicaciones del que ya existe. En estas redes, según los indicadores que utilizamos, los actores que producen recursos naturales tienen capacidades menores que otros actores y no suelen desempeñar un papel central en la difusión o creación de conocimiento en las redes estudiadas. El nivel de cohesión en las redes es diverso: solo una de ellas presenta valores relativamente altos en los tres indicadores utilizados para evaluar la cohesión. Por otro lado, solo una red presenta también un nivel elevado de apertura fuera del núcleo de los recursos naturales, aunque dicha apertura se orienta más hacia actividades de docencia e investigación que hacia otras actividades productivas.

Más allá de algunas anécdotas, tampoco hemos hallado evidencia robusta de que en estas redes se esté creando conocimiento que se utilice en otros sectores de actividad de la economía, a pesar de que existen otros estudios en los que sí se han encontrado efectos de esta naturaleza (véase Lengyel y Bottino, 2011; Kuramoto y Sagasti, 2008; Velho y Velho, 2008).

Sin embargo, el hecho de que no hayamos hallado esa evidencia puede ser resultado del diseño de la investigación, ya que es probable que en el estudio de las redes se requiera considerar períodos de tiempo más largos e incluir una multiplicidad de actores para captar esos efectos. Es importante mencionar que el análisis empírico de las redes sociales no carece de debilidades y puntos que, sin duda, son perfectibles. En primer lugar, y como se expuso en el trabajo, las redes reconstruidas en relación con cada país no son estrictamente comparables entre sí. En las dos últimas columnas del cuadro 3 se advierte sobre las diferencias en la recopilación de datos de las distintas redes y el impacto de dichas diferencias en la comparabilidad de los distintos indicadores. A la luz de esto, hemos tratado de ser cautos y dar más peso al análisis de cada red en sí misma que a la comparación entre redes. Por otro lado, cada red presentada es una reconstrucción mínima de la verdadera red subyacente, que con seguridad abarca más vínculos de conocimiento, más actores y tipologías más diversas de vínculos y actores.

En particular, estas limitaciones metodológicas impiden ver el impacto que el uso o la creación de conocimiento científico útil para producir recursos naturales tiene sobre la innovación de otros actores que no necesariamente forman parte de la misma cadena de valor y que, por lo tanto, no se relacionan mediante vínculos directos con los actores que producen recursos naturales. Creemos que, en futuras investigaciones, se debería profundizar en la exploración de este asunto.

Las clasificaciones y simplificaciones analíticas, así como la limitación de recursos para explorar más en profundidad cada caso, hacen que solo podamos aproximarnos a un conocimiento incompleto de la red, que, sin embargo, nos ha permitido extraer enseñanzas interesantes. 
Para concluir, señalamos un número de elementos que surgieron durante la investigación y que consideramos importantes en lo que atañe al diseño de políticas del sector. En primer lugar, en el estudio se identificó un área de intervención (de política industrial, y de ciencia y tecnología) que no se suele considerar cuando se piensa en políticas orientadas a los sectores de los recursos naturales: las redes de conocimiento que se generan en asociación con los sectores de los recursos naturales. Establecimos que estas redes existen, que en ellas se asocian agentes del sector privado con actores académicos y encargados de formular políticas, y que, con el objetivo de satisfacer las necesidades de los sectores de los recursos naturales, dichos agentes y actores aplican y difunden el conocimiento científico existente y, en alguna medida, crean conocimiento nuevo.

Cuando pensamos en políticas orientadas al aprovechamiento de las oportunidades que surgen en asociación con las actividades basadas en los recursos naturales, solemos considerar estos últimos como fuentes de divisas o impuestos. Sin embargo, en la medida en que en estos sectores se utiliza conocimiento científico y se desarrollan redes, se abre un área nueva de posible intervención que no se puede ignorar.

En este sentido, se pueden diseñar políticas que den soporte a la construcción de redes de conocimiento relativas a la producción e innovación en materia de recursos naturales. Esto se debe hacer no solo porque a partir de este estudio sabemos que las redes de conocimiento son funcionales a la innovación en el sector de los recursos naturales, sino también porque la literatura nos ha enseñado que, cuanto más desarrolladas y abiertas sean las redes y más capaces los actores que participan, mejores son los resultados en términos de innovación y creación de conocimiento en los sistemas de innovación en general.

En segundo lugar, las capacidades de los actores se relacionan con el papel que ellos juegan en la red. Encontramos que, en general, los actores con capacidades mayores desempeñan un papel central en la difusión de conocimiento en la red. Este hallazgo tiene implicaciones para el diseño de herramientas de intervención, ya que convendría apuntar a que los actores con capacidades elevadas participen en las redes que se promueven.

En tercer lugar, en el estudio se señala que, en general, en las redes identificadas se tiende a utilizar conocimiento existente más que a crear conocimiento nuevo. Asimismo, encontramos poca evidencia de que este conocimiento nuevo esté migrando a otros sectores. Esta parece ser un área posible de intervención en materia de política. Tanto el sector de los recursos naturales como otras actividades con las que su matriz de conocimiento se pueda vincular se beneficiarían si se intensificaran las prácticas y las vinculaciones que propician la creación de nuevo conocimiento. En este sentido, se podría intervenir incentivando acuerdos de cooperación en investigación entre empresas y el sector científico, o entre las empresas entre sí, o también promoviendo la apertura de las redes y la integración de actores con distintos tipos de conocimientos.

Por último, encontramos algún indicio de que el tipo de actores involucrados parece afectar las características estructurales de las redes. Por ejemplo, la única red centrada en torno a la subsidiaria de una multinacional presenta ciertas particularidades: ese actor no ocupa un lugar central en la difusión de conocimiento y la red que conforma es relativamente cerrada. De esta forma, las características específicas de los actores que participan pueden condicionar el potencial de difusión y creación de conocimiento, y deben ser tomadas en cuenta en el momento de pensar políticas orientadas a incentivar el desarrollo de redes. 


\section{Bibliografía}

Aboal, D., F. Rovira y F. Veneri (2014), "Innovación y redes de conocimiento: el caso de una empresa del sector forestal en Uruguay", Serie Documentos del Reporte Anual 2014. Recursos Naturales y Desarrollo, Montevideo, Red Sudamericana de Economía Aplicada (Red Sur).

Ahuja, G. (2000), "Collaboration networks, structural holes and innovation: a longitudinal study", Administrative Science Quarterly, vol. 45, № 3, SAGE.

Ahuja, G. y R. Katila (2001), "Technological acquisitions and the innovation performance of acquiring firms: a longitudinal study", Strategic Management Journal, vol. 22, No 3, Wiley.

Ahuja, G., G. Soda y A. Zaheer (2012), "Introduction to the special issue: the genesis and dynamics of organizational networks", Organization Science, vol. 23, № 2, INFORMS.

Altenburg, T. y J. Meyer-Stamer (1999), "How to promote clusters: policy experiences from Latin America", World Development, vol. 27, № 9, Amsterdam, Elsevier.

Andersen, A. (2015), "A functions approach to innovation system building in the South: the pre-proálcool evolution of the sugarcane and biofuel sector in Brazil", Innovation and Development, vol. 5, $\mathrm{N}^{\circ} 1$, Taylor \& Francis.

Andersen, A. y otros (2015), Natural Resources, Innovation and Development, Aalborg Universitetsforlag.

Arza, V., E. López y A. Marín (2014), "Actividades de innovación y redes de conocimiento en recursos naturales. El caso del mejoramiento bovino en Argentina", Serie Documentos del Reporte Anual 2014. Recursos Naturales y Desarrollo, Montevideo, Red Sudamericana de Economía Aplicada (Red Sur).

Auty, R. (1997), "Natural resource endowment, the state and development strategy", Journal of International Development, vol. 9, № 4, Wiley. (1993), Sustaining Development in Mineral Economies: The Resource Curse Thesis, Nueva York, Routledge.

Bell, M. y E. Giulani (2007), "Catching up in the global wine industry: innovation systems, cluster knowledge networks and firm-level capabilities in Italy and Chile", International Journal of Technology and Globalisation, vol. 3, No 2 .

Benavente, J. M. (2014), "El desafío de la innovación en la industria minera: el caso de Chile", Serie Documentos del Reporte Anual 2014. Recursos Naturales y Desarrollo, Montevideo, Red Sudamericana de Economía Aplicada (Red Sur).

Bervejillo, J., F. Mila y F. Bertamini (2011), "El crecimiento de la productividad agropecuaria 1980-2010", Anuario OPYPA 2011, Montevideo, Oficina de Programación y Política Agropecuaria (OPYPA)/Ministerio de Ganadería, Agricultura y Pesca (MGAP).

Breschi, S. y F. Malerba (2001), "The geography of innovation and economic clustering: some introductory notes", Industrial and Corporate Change, vol. 10, № 4, Oxford University Press.

Cabral, R. (1998), "From university-industry interfaces to the making of a science park: Florianopolis, Southern Brazil", International Journal of Technology Management, vol. 16, № 8.

COCHILCO (Comisión Chilena del Cobre) (2009), "Biolixiviación: desarrollo actual y sus expectativas", Desarrollo minero en Chile: análisis y desafíos, Santiago.

Coleman, J. (1988), "Social capital in the creation of human capital", American Journal of Sociology, vol. 94, Chicago, The University of Chicago Press.

Cowan, R. (2005), "Network models of innovation and knowledge diffusion", Clusters, Networks and Innovation, S. Breschi y F. Malerba (eds.), Nueva York, Oxford University Press.

Crespi, G., J. Katz y J. Olivari (2016), "Innovación, actividades basadas en recursos naturales y cambio estructural: la emergencia de empresas de servicios intensivos en conocimiento", La política de innovación en América Latina y el Caribe: nuevos caminos, J. Olivari y J. C. Navarro (eds.), Washington, D.C., Banco Interamericano de Desarrollo (BID).

Csardi, G. y T. Nepusz (2006), "The igraph software package for complex network research", InterJournal, Complex Systems, vol. 1695, № 5.

Dantas, E. (2011), "The evolution of the knowledge accumulation function in the formation of the Brazilian biofuels innovation system", International Journal of Technology and Globalisation, vol. 5, № 3-4.

Duysters, G. y W. Schoenmakers (2006), "Learning in strategic technology alliances", Technology Analysis \& Strategic Management, vol. 18, № 2, Taylor \& Francis.

Etzkowitz, H., J. M. Carvalho de Mello y M. Almeida (2005), "Towards 'meta-innovation' in Brazil: the evolution of the incubator and the emergence of a triple helix", Research Policy, vol. 34, № 4, Amsterdam, Elsevier. 
Etzkowitz, H. y L. Leydesdorff (2000), "The dynamics of innovation: from national systems and 'Mode 2' to a triple helix of university-industry-government relations", Research Policy, vol. 29, № 2, Amsterdam, Elsevier.

Figueiredo, P. N. (2010), "Discontinuous innovation capability accumulation in latecomer natural resourceprocessing firms", Technological Forecasting and Social Change, vol. 77, Nㅜ 7, Amsterdam, Elsevier.

Fundación Chile (2014), Proveedores de la minería chilena. Estudio de caracterización 2014, Santiago.

(2012), Proveedores de la minería chilena. Estudio de caracterización 2012, Santiago.

Gelb, A. (1988), Oil Windfalls: Blessing or Curse?, Nueva York, Oxford University Press.

Giuliani, E. (2013), "Network dynamics in regional clusters: evidence from Chile", Research Policy, vol. 42, $N^{\circ} 8$, Amsterdam, Elsevier.

(2007), "The wine industry: persistence of tacit knowledge or increased codification? Some implications for catching-up countries”, International Journal of Technology and Globalisation, vol. 3, № 2-3.

Giuliani, E. y V. Arza (2009), "What drives the formation of 'valuable' university-industry linkages? An underexplored question in a hot policy debate", Research Policy, vol. 38, № 6, Amsterdam, Elsevier.

Giuliani, E. y M. Bell (2005), "The micro-determinants of meso-level learning and innovation: evidence from a Chilean wine cluster", Research Policy, vol. 34, № 1, Amsterdam, Elsevier.

Gulati, R. y M. Gargiulo (1999), "Where do inter-organizational networks come from?", American Journal of Sociology, vol. 104, № 5, Chicago, The University of Chicago Press.

Gylfason, T., T. Herbertsson y G. Zoega (1999), "A mixed blessing", Macroeconomic Dynamics, vol. 3, № 2, Cambridge University Press.

Hagedoorn, J. y G. Duysters (2000), "The effects of mergers and acquisitions on the technological performance of companies in high tech environment", Maastricht, Universidad de Maastricht, inédito.

Hirschman, A. O. (1961), La estrategia del desarrollo económico, Ciudad de México, Fondo de Cultura Económica.

lizuka, M. y J. Katz (2015), "Globalisation, sustainability and the role of institutions: the case of the Chilean salmon industry", Tijdschrift voor economische en sociale geografie, vol. 106, № 2, Wiley.

Kolhi, M. M., L. E. Cubilla y L. Viedma (2009), Segundo Seminario Nacional de Trigo. Del grano al pan, Asunción, Cámara Paraguaya de Exportadores de Cereales y Oleaginosas (CAPECO).

Kuramoto, J. y F. Sagasti (2008), "Cleaning pollution: from mining to environmental remediation", Resource Intensity, Knowledge and Development: Insights from Africa and South America, J. Lorentzen (ed.), Ciudad del Cabo, Human Science Research Council.

Lengyel, M. F. y G. Bottino (2011), "La producción en red en Argentina y sus fundamentos institucionales", Desarrollo Económico. Revista de Ciencias Sociales, vol. 1, № 202/203, Buenos Aires, Instituto de Desarrollo Económico y Social.

Levin, J. (1960), The Export Economies: Their Pattern of Development in Historical Perspective, Cambridge, Massachusetts, Harvard University Press.

Lorentzen, J. (2005), "Lateral migration in resource-intensive economies: technological learning and industrial policy" [en línea] http://www.hsrc.ac.za/en/research-data/ktree-doc/1287.

Lundvall, B. L. y otros (2002), "National systems of production, innovation and competence building", Research Policy, vol. 31, № 2, Amsterdam, Elsevier.

Marín, A., L. Navas-Alemán y C. Pérez (2015), "Natural resource industries as a platform for the development of knowledge intensive industries", Tijdschrift voor economische en sociale geografie, vol. 106, № 2.

Marín, A. y L. Stubrin (2015), "Innovation in natural resources: new opportunities and new challenges. The case of the Argentinian seed industry", Working Paper Series, № 2015-15 [en línea] https://www.merit. unu.edu/publications/working-papers/abstract/?id=5654.

Marín, A., L. Stubrin y J. J. da Silva (2015b), "KIBS associated to natural resource based industries: seeds innovation and regional providers of the technology services embodied in seeds in Argentina and Brazil, 2000-2014", Discussion Paper, № IDB-DP-375, Washington, D.C., Banco Interamericano de Desarrollo (BID).

Mazzoleni, R. y R. R. Nelson (2007), "Public research institutions and economic catch-up", Research Policy, vol. 36, No 10, Amsterdam, Elsevier.

Morris, M., R. Kaplinsky y D. Kaplan (2012), “'One thing leads to another' - Commodities, linkages and industrial development", Resources Policy, vol. 37, № 4, Amsterdam, Elsevier.

Mowery, D. C., J. E. Oxley y B. S. Silverman (1996), "Strategic alliances and interfirm knowledge transfer", Strategic Management Journal, vol. 17, № S2, Wiley.

Nankani, G. (1980), "Development problems of nonfuel mineral exporting countries", Finance and Development, vol. $17, \mathrm{~N}^{\circ} 1$. 
Nurkse, R. (1958), "Trade fluctuations and buffer policies of low-income countries", Kyklos, vol. 11, № 2, Wiley. Pérez, C. (2010), "Technological revolutions and techno-economic paradigms", Cambridge Journal of Economics, vol. 34, № 1, Oxford University Press.

Powell, W. y otros (1999), "Network position and firm performance: organizational returns to collaboration in the biotechnology industry", Research in the Sociology of Organizations, vol. 16, № 1.

Prebisch, R. (1962), "El desarrollo económico de la América Latina y algunos de sus principales problemas", Boletín Económico de América Latina, vol. 7, № 1, Santiago, Naciones Unidas.

R Development Core Team (2014), "R: a language and environment for statistical computing", Viena, The R Foundation.

Rees, K. (2005), "Interregional collaboration and innovation in Vancouver's emerging high-tech cluster", Tijdschrift voor economische en sociale geografie, vol. 96, №3, Wiley.

Rosenkopf, L. y P. Almeida (2003), "Overcoming local search through alliance and mobility", Management Science, vol. 49, N 6, INFORMS.

Sachs, J. y A. Warner (1995), "Natural resource abundance and economic growth", NBER Working Paper, № 5398, Cambridge, Massachusetts, Oficina Nacional de Investigaciones Económicas.

Schmitz, H. y K. Nadvi (1999), "Clustering and industralization: introduction", World Development, vol. 27, $N^{\circ}$ 9, Amsterdam, Elsevier.

Servín, M. B. y A. Rojas (2014), "El sector del trigo en el Paraguay: potencialidades de innovación y aprendizajes", Serie Documentos del Reporte Anual 2014. Recursos Naturales y Desarrollo, Montevideo, Red Sudamericana de Economía Aplicada (Red Sur).

Singer, H. (1975), The Strategy of International Development: Essays in the Economics of Backwardness, Londres, Macmillan.

- (1950), "The distribution of gains between investing and borrowing countries", American Economic Review, vol. 40, N², Nashville, Tennessee, American Economic Association.

Smith, K. (2007), "Innovation and growth in resource-based economies", CEDA Growth, № 58.

Stubrin, L. (2013), "High-tech activities in emerging countries. A network perspective on the Argentinian biotech activity", Maastricht, Universidad de Maastricht.

Uzzi, B. (1996), "The sources and consequences of embeddedness for the economic performance of organizations: the network effect", American Sociological Review, vol. 61, № 4, Washington, D.C., Asociación Estadounidense de Sociología.

Velho, L. y P. Velho (2008), "The development of sugar-based plastic in Brazil", Resource Intensity, Knowledge and Development: Insights from Africa and South America, J. Lorentzen (ed.), Ciudad del Cabo, Human Science Research Council.

Ville, S. y O. Wicken (2012), "The dynamics of resource-based economic development: evidence from Australia and Norway", Industrial and Corporate Change, vol. 22, № 5, Oxford University Press.

Wasserman, S. y K. Faust (1998), Social Network Analysis: Methods and Applications, Nueva York, Cambridge University Press.

Wheeler, D. (1984), "Sources of stagnation in sub-Saharan Africa", World Development, vol. 12, № 1 , Amsterdam, Elsevier. 


\section{Anexo A1}

Cuadro A1.1

Actores entrevistados de cada red

\begin{tabular}{|c|c|c|c|c|}
\hline Red & & Actor entrevistado & $\begin{array}{l}\text { Actor que } \\
\text { produce recursos } \\
\text { naturales }\end{array}$ & Tipo de actor \\
\hline \multirow{16}{*}{ 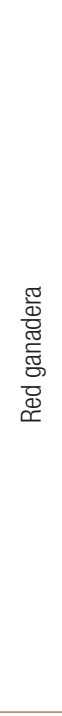 } & 1 & IRAC-BIOGEN & & Empresa privada (ego) \\
\hline & 2 & Cabaña Sierras Chicas & $X$ & Empresa privada (cabaña) \\
\hline & 3 & Tambo Don Antonio & $x$ & Empresa privada (tambo) \\
\hline & 4 & Cabaña La Sultana & $x$ & Empresa privada (cabaña) \\
\hline & 5 & Cabaña Los Socavones & $x$ & Empresa privada (cabaña) \\
\hline & 6 & Cabaña Las Pencas & $x$ & Empresa privada (cabaña) \\
\hline & 7 & Cabaña La Lilia & $x$ & Empresa privada (cabaña) \\
\hline & 8 & Instituto Veterinario Chamical & & Empresa privada \\
\hline & 9 & $\begin{array}{l}\text { Centro de Excelencia en Productos y } \\
\text { Procesos de Córdoba (CEPROCOR) }\end{array}$ & & Organismo público de investigación \\
\hline & 10 & $\begin{array}{l}\text { Instituto Nacional de Tecnología Agropecuaria } \\
\text { (INTA) Castelar, Centro de Investigación en Ciencias } \\
\text { Veterinarias y Agronómicas (CICVYA) }\end{array}$ & & Organismo público de investigación \\
\hline & 11 & Universidad Nacional de Córdoba (Ciencias Agropecuarias) & & Universidad \\
\hline & 12 & Universidad Nacional de Villa María (Veterinaria) & & Universidad \\
\hline & 13 & Universidad Nacional de Río Cuarto (Veterinaria) & & Universidad \\
\hline & 14 & Universidad de Buenos Aires (Agronomía) & & Universidad \\
\hline & 15 & Universidad Nacional de San Martín (Biotecnología) & & Universidad \\
\hline & 16 & Universidad Nacional de la Plata (Veterinaria) & & Universidad \\
\hline \multirow{8}{*}{ 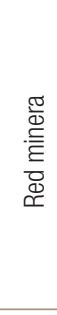 } & 1 & Aguamarina S. A. & & Empresa privada (ego) \\
\hline & 2 & Essbio & & Empresa privada \\
\hline & 3 & VialCorp & & Empresa privada \\
\hline & 4 & Aplik & & Empresa privada \\
\hline & 5 & Harsco & & Empresa multinacional \\
\hline & 6 & NTC & & Laboratorio privado \\
\hline & 7 & Clúster Minero & & Asociación \\
\hline & 8 & Fundación Chile & & Otro (fundación público-privada) \\
\hline \multirow{12}{*}{ 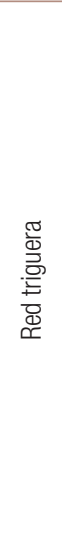 } & 1 & Sem-Agro & $x$ & Empresa privada \\
\hline & 2 & Hilagro & & Empresa privada \\
\hline & 3 & Agro Santa Rosa & $x$ & Empresa privada \\
\hline & 4 & Dekalpar & $x$ & Empresa privada \\
\hline & 5 & Semillas Criciuma & $x$ & Empresa privada \\
\hline & 6 & $\begin{array}{l}\text { Instituto Paraguayo de Tecnología Agraria (IPTA), Cámara } \\
\text { Paraguaya de Exportadores de Cereales y Oleaginosas } \\
\text { (CAPECO) e Instituto de Biotecnología Agrícola (INBIO) }\end{array}$ & & Organismo público de investigación \\
\hline & 7 & Centro Tecnológico Agropecuario del Paraguay (CETAPAR) & & Organización no gubernamental \\
\hline & 8 & Cooperativa Pindo & $x$ & Cooperativa \\
\hline & 9 & Colonias Unidas & $x$ & Cooperativa \\
\hline & 10 & Cooperativa La Paz & $x$ & Cooperativa \\
\hline & 11 & $\begin{array}{l}\text { Cooperativa de Producción Agroindustrial } \\
\text { Santa María Ltda. (COOPASAM) }\end{array}$ & $x$ & Cooperativa \\
\hline & 12 & Sociedad Cooperativa Pirapó Agricola Ltda. & $X$ & Cooperativa \\
\hline
\end{tabular}


Cuadro A1.1 (conclusión)

\begin{tabular}{|c|c|c|c|c|}
\hline Red & & Actor entrevistado & $\begin{array}{l}\text { Actor que } \\
\text { produce recursos } \\
\text { naturales }\end{array}$ & Tipo de actor \\
\hline \multirow{17}{*}{ 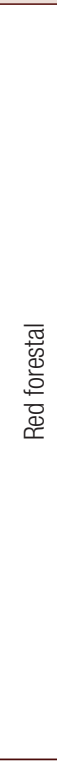 } & 1 & Theobaldus Jauken & & Empresa privada \\
\hline & 2 & Ing. Agrim. Eduardo Guerra de Geofly & & Empresa privada \\
\hline & 3 & CSI Ingenieros & & Empresa privada \\
\hline & 4 & GeoAmbiente & & Empresa privada \\
\hline & 5 & SPT Consultores & & Empresa privada \\
\hline & 6 & Turboflow & & Empresa privada \\
\hline & 7 & Xternum & & Empresa privada \\
\hline & 8 & Depto. Técnico de UPM en Fray Bentos, Uruguay & & Empresa multinacional \\
\hline & 9 & Montes del Plata & $x$ & Empresa multinacional \\
\hline & 10 & Ellegaard & & Empresa multinacional \\
\hline & 11 & Netafim & & Empresa multinacional \\
\hline & 12 & Vivero Santana & $x$ & Empresa multinacional \\
\hline & 13 & $\begin{array}{l}\text { Instituto Nacional de Investigación Agropecuaria } \\
\text { (INIA), Departamento Forestal }\end{array}$ & & Organismo público de investigación \\
\hline & 14 & INIA, Micropropagación & & Organismo público de investigación \\
\hline & 15 & Universidad del Trabajo del Uruguay (UTU) & & Universidad \\
\hline & 16 & $\begin{array}{l}\text { Departamento de Producción Forestal y Tecnología de la } \\
\text { Madera y Departamento de Suelos y Aguas de la Facultad de } \\
\text { Agronomía (FAGRO) de la Universidad de la República (UDELAR) }\end{array}$ & & Universidad \\
\hline & 17 & Instituto de Pesquisas e Estudos Florestais (IPEF) & & Organización no gubernamental \\
\hline
\end{tabular}

Fuente: Elaboración propia. 


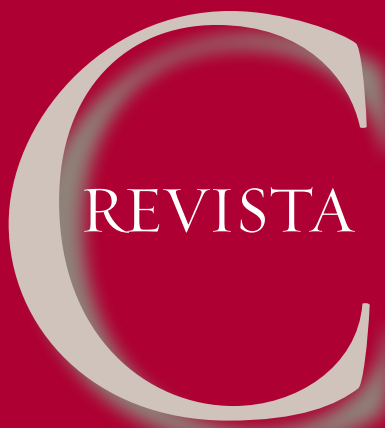

www.cepal.org/revista 